\title{
Un indicador de accesibilidad a unidades de servicios clave para ciudades mexicanas: fundamentos, diseño y aplicación
}

\author{
Carlos F. Garrocho Rangel* \\ JuAn Campos Alanís***
}

\begin{abstract}
Several institutions in Mexico are currently working in collaboration with the Federal Government and the UN-Habitat Programme towards building up some urban observatories to consolidate Observatorio Urbano Nacional - Red oul (National Urban Observatory). Some of the main aims of this project is to provide some indicators that are actually useful and that can be used systematically in the decision making process of urban planers. In this paper we propose the design of an indicator of public and private service accessibility that could be applied in the urban planning tasks in a national context and thus could enrich the consolidation of urban observatories in Mexico. The paper contributes to the current debate taking place in Mexico about the importance of public and private service accessibility, as an indicator of metropolitan performance and quality.
\end{abstract}

Keywords: accessibility, accessibility indicator, public services, urban observatories.

\section{Resumen}

En México, diversas instituciones están trabajando con el gobierno federal y el Programa Hábitat de la Organización de las Naciones Unidas en la construcción de observatorios urbanos que conformen el Observatorio Urbano Nacional (Red OUL). Uno de los propósitos principales de este proyecto es contar con sistemas de indicadores realmente útiles, que apoyen cotidianamente la toma de decisiones de los planificadores urbanos. En este trabajo se propone el diseño de un indicador de accesibilidad a servicios públicos y privados que pueda ser utilizado cotidianamente en tareas de planeación urbana en el contexto nacional, y que enriquezca la construcción de observatorios urbanos en México. Así, este artículo puede contribuir al debate que actualmente se lleva a cabo en México sobre la importancia de la accesibilidad a servicios públicos y privados, como un indicador de desempeño y de calidad metropolitana.

Palabras clave: accesibilidad, indicador de accesibilidad, servicios públicos, observatorios urbanos

* El Colegio Mexiquense, A.c. Correo-e: cgarrocho@cmq.edu.mx.

** Universidad Autónoma del Estado de México. Correo-e: caaj7007@yahoo.com. 


\section{Introducción}

La planeación eficaz de las ciudades requiere de información precisa y útil tanto de la situación de las ciudades, como de sus tendencias futuras. Ello, aunado a que cada vez es mayor la proporción de la población que vive en áreas urbanas, ha motivado a los gobiernos tanto nacionales como locales y a las principales organizaciones internacionales a realizar enormes esfuerzos por contar con buenos indicadores sobre la situación actual y el futuro de las ciudades (un-Habitat, 2005a; Kingsley, 1998).

En este sentido, el reto es no sólo construir sino también mantener actualizado un sistema de indicadores realmente útiles que apoye cotidianamente la toma de decisiones de los administradores urbanos y el diseño de las políticas de desarrollo de las ciudades, y que permita dar prioridad y orientar los esfuerzos públicos y privados hacia los espacios urbanos más necesitados. Ese esfuerzo, de carácter internacional, encuentra su más clara expresión en el Programa de las 1000 Ciudades de la Organización de las Naciones Unidas, del cual México forma parte desde sus primeras etapas (un-Habitat, 2005a y 2005b).

Durante 2005, en respuesta a un convenio firmado con la Organización de las Naciones Unidas, el gobierno mexicano, por medio del Consejo Nacional de Ciencia y Tecnología, ha apoyado la construcción de un Observatorio Urbano Nacional constituido en su primera etapa por alrededor de 22 observatorios urbanos. ${ }^{1}$ Esos observatorios registran y dan seguimiento a un conjunto de indicadores básicos recomendados por la Organización de las Naciones Unidas, pero también promueven la construcción de indicadores más útiles y acordes a las necesidades locales que apoyen el diseño de políticas de desarrollo urbano a escalas espaciales suburbanas.

Tanto en el país ${ }^{2}$ como en el Área Metropolitana de Toluca (АМт), que es una de las ciudades en las que se construye actualmente un observatorio urbano, se ha detectado la necesidad urgente de contar con indicadores de accesibilidad a servicios públicos clave para el bienestar de grupos de población vulnerables.

${ }^{1}$ Uno de los cuales es Metrosum (Observatorio Metropolitano de Toluca), cuya construcción está a cargo de un grupo de investigadores de El Colegio Mexiquense y de la Universidad Autónoma del Estado de México.

${ }^{2}$ Esto es evidente si se revisan las Reglas de Operación 2005 del Programa de Desarrollo Humano Oportunidades (Sedesol, 2005), que es el programa de desarrollo social más importante del gobierno federal desde el año 2000. 
La estrategia de presentación del artículo se articula en torno a siete secciones y un anexo. En la primera sección se presentan los objetivos del artículo, que deberán situarse en el marco del esfuerzo nacional por construir un Observatorio Urbano Nacional. En la segunda se hace una amplia revisión de los diversos enfoques conceptuales y metodológicos que reporta la literatura para entender y estimar la accesibilidad, de la que se concluye que el enfoque de interacción espacial es quizá el más sólido y práctico que existe para estimar la accesibilidad a y de los servicios a escala metropolitana. Esa sección es particularmente importante para apoyar la construcción de observatorios urbanos en México, porque sintetiza gran parte de la literatura reciente sobre indicadores de accesibilidad, que no ha sido ampliamente cubierta en nuestro país. En la tercera sección se propone el diseño de un índice de accesibilidad a unidades de servicio en ciudades mexicanas y se justifica su estructura conceptual y operativa. Cabe mencionar que se trata de un índice de interacción espacial derivado del comportamiento territorial de los usuarios de los servicios de salud mayores de 65 años en el AMT. En la cuarta sección se definen operativamente los componentes del índice de accesibilidad para los servicios de salud, especialmente la manera como se determina y dimensiona la demanda (población usuaria por AGEB, área geoestadística básica), la oferta disponible (los servicios en las unidades de salud) y los costos de transporte que se deben remontar para poner en contacto a la población con los servicios médicos. ${ }^{3}$ En la quinta sección se pone a prueba el diseño del índice de accesibilidad para ciudades mexicanas que se presentó en la tercera y cuarta secciones. Se estiman los índices de accesibilidad para los servicios de salud orientados a la población mayor de 65 años y se analizan los resultados; y en la sexta sección se simulan algunos escenarios con el fin ilustrar la utilidad del índice de accesibilidad en algunas tareas de planeación metropolitana. Finalmente, en la séptima sección se presentan las principales conclusiones del trabajo. Al final del texto se incluye un extenso listado de la bibliografía consultada y un anexo en donde se explica detalladamente, mediante un ejemplo, el cálculo y aplicación del índice de accesibilidad que se propone en este artículo.

${ }^{3}$ Los costos de transporte se pueden estimar en unidades diversas, dependiendo de la información disponible: unidades monetarias, de energía, de distancia...; o en unidades subjetivas: percepción de costos, de incomodidades, de riesgos...; o incluso mediante una mezcla de unidades objetivas y subjetivas. En este trabajo se utilizan unidades de distancia. 


\section{Objetivos}

Los objetivos de este artículo son los siguientes:

- Diseñar un indicador de accesibilidad a servicios públicos ${ }^{4}$ con sólidos fundamentos conceptuales, que por su sencillez, utilidad y requerimientos de información pueda ser utilizado en tareas de planeación urbana en el contexto nacional, de tal manera que enriquezca la construcción de observatorios urbanos en México.

- Poner a prueba el diseño conceptual y operativo del indicador de accesibilidad a servicios públicos y privados en una zona de estudio de alta complejidad, como el AMT.

- Contribuir con propuestas concretas al debate que actualmente se lleva a cabo en México sobre la importancia de la accesibilidad a servicios públicos y privados, como un indicador de desempeño y de calidad metropolitana. ${ }^{5}$

\section{Accesibilidad: qué es y cómo se mide}

Desde hace décadas, el concepto de accesibilidad ha sido objeto de atención de diversas disciplinas; sin embargo, no parece existir una definición generalmente aceptada del concepto. La accesibilidad es uno de esos conceptos que parecen de fácil comprensión hasta que se enfrenta el problema de definirlo y medirlo. Quizá por eso contrasta la intensidad de su uso con las pocas definiciones explícitas que reporta la literatura (Bath et al., 2000).

${ }^{4}$ Aunque también se podría aplicar a servicios privados.

${ }^{5} \mathrm{La}$ accesibilidad a servicios básicos es un indicador de calidad urbana, que en este trabajo se estima a escala de áreas geoestadísticas básicas (AGEB). Esto se complementa con la estimación de la accesibilidad de las unidades de servicio, a la que consideramos un indicador de desempeño urbano. Por tanto, en este trabajo la calidad urbana está relacionada con la población (con la demanda), mientras que el desempeño urbano está asociado con las unidades de servicio (con la oferta y, por lo tanto, con el desempeño de los administradores urbanos). Los resultados de este trabajo permitirán identificar en el AMT zonas y unidades de servicio con baja accesibilidad y explorar alternativas para elevar la accesibilidad y reducir las desigualdades, lo que tal vez ayude a los administradores urbanos a dar prioridad a determinados proyectos y a diseñar políticas públicas más eficaces y equitativas. 


\subsection{Una definición operativa de accesibilidad}

No es el propósito en este trabajo proponer una definición teórica, exhaustiva y general del concepto de accesibilidad, pero, dados los objetivos de este texto, sí se requiere establecer una definición operativa que nos permita medirla, tanto para zonas de la ciudad (AGEB) como para las unidades de servicio. Con ese fin se revisan a continuación dos definiciones de libro de texto ampliamente aprobadas en la comunidad académica, y derivamos una más que, al mismo tiempo que es coherente con las definiciones examinadas, resulta útil para lograr los objetivos de este trabajo.

Una de las definiciones de accesibilidad más aceptadas es la de Brian Goodall (1987), quien -en su famoso diccionario de geografía humana- propone que "accesibilidad es la facilidad con la que se puede alcanzar un cierto sitio (destino), desde otros puntos en el territorio (orígenes), por lo que sintetiza las oportunidades de contacto e interacción entre determinados orígenes y destinos". Dos aspectos interesa resaltar de esta definición. Uno es la parte que habla de las oportunidades (o probabilidades) de contacto e interacción, que es lo que Alun E. Joseph y David R. Phillips (1984) llaman accesibilidad potencial, para diferenciarla de la utilización efectiva del servicio, a la que llaman accesibilidad real. La otra es el carácter agregado de la definición: según Goodall, accesibilidad se refiere a las oportunidades de interacción entre orígenes y destinos (es decir, entre áreas y/o puntos) más que a la interacción efectiva entre individuos y destinos. En síntesis, la definición de Goodall es probabilística y agregada.

Por su parte, la definición de Ronald J. Johnston, Derek Gregory y David M. Smith (2000) -en su también muy reconocido diccionario de geografía humana- va en la misma dirección que la de Goodall, y también es probabilística y agregada: “accesibilidad es la oportunidad de interacción y contacto entre orígenes y destinos". Ahora bien, esto no significa que la accesibilidad no se pueda entender de otras maneras -en el nivel individual, por ejemplo-, y tanto Goodall como Johnston, Gregory y Smith exploran las múltiples dimensiones del concepto de accesibilidad. ${ }^{6}$ Sin embargo, las definiciones de orden general que subrayan la dimensión espacial de la accesibilidad son suficientes para los propósitos de este trabajo.

${ }^{6}$ El cual ya ha sido ampliamente discutido en otro lado para el caso del valle de Toluca (Garrocho, 1990a, 1990b y 1995). 
Así, a partir de las definiciones revisadas se propone que en este trabajo se entienda por accesibilidad a unidades de servicios: "el potencial de interacción entre la población objetivo que vive en cada AGEB del Área Metropolitana de Toluca y las unidades de servicios disponibles en la ciudad". Esta definición tiene la ventaja de que puede adecuarse para cualquier grupo de población, para cualquier tipo de servicio tanto público como privado, y para cualquier ciudad del país.

\subsubsection{Consideraciones complementarias a la definición operativa}

Una vez establecida la definición operativa de accesibilidad que se utilizará en este trabajo, es necesario puntualizar algunos aspectos complementarios. Quizá el primer punto que habría que aclarar es si el concepto de accesibilidad se refiere a la población, a las unidades de servicio o a ambas. Es decir, si se trata de accesibilidad a determinados destinos (dando prioridad a la visión de los usuarios en el origen), o de accesibilidad de las unidades del servicio (en cuyo caso es un atributo del destino). Lo que se puede decir es que ambos conceptos son válidos, indican cosas distintas y se han utilizado ampliamente, como lo reporta la literatura desde hace tiempo (Bach, 1981). Así, en este trabajo se entiende la accesibilidad como un atributo compartido, tanto del origen (usuarios potenciales) como del destino (unidades de servicio), ya que los relaciona de manera directa.

Por lo tanto, el enfoque desde el origen (zonas de la ciudad, en este caso AGEB) permite estimar la accesibilidad que tiene la demanda -o un segmento de la demanda- localizada en cierta parte de la ciudad, a la oferta de servicios disponibles (lo que aquí llamamos calidad urbana); mientras que el enfoque desde el destino (desde las unidades de servicio) permite estimar qué tan accesible es la oferta -o un segmento de la oferta- a la población demandante del servicio (lo que aquí llamamos desempeño urbano). Así, en este trabajo calidad urbana es la accesibilidad vista desde el punto de vista de la demanda, mientras que desempeño urbano es la accesibilidad vista desde la perspectiva de la oferta.

Por otro lado, es oportuno señalar que el concepto de accesibilidad tiene dos componentes básicos, uno físico y otro social, en el más amplio sentido del término. El componente físico se relaciona con la distancia geográfica (como quiera que se estime) que separa al usuario potencial del punto de servicio, expresa la 
proximidad espacial entre ambos y representa la accesibilidad locacional del servicio y/o de los usuarios (según la perspectiva que se adopte). El componente social se refiere a la distancia social que existe entre el usuario potencial y el servicio, e involucra las características de ambos. ${ }^{7}$

Por ello, existen dos aproximaciones básicas para el estudio y medición de la accesibilidad de los servicios, la de accesibilidad potencial y la de accesibilidad revelada. La primera se relaciona con el componente físico del concepto, se centra en la accesibilidad potencial de los servicios e involucra la localización tanto de la oferta (unidades de servicio) como de la demanda (usuarios potenciales). La segunda considera el componente social de la accesibilidad y se preocupa por estimar la accesibilidad revelada de los servicios usando, principalmente, datos de utilización (encuestas y registros médicos, principalmente) (Joseph y Phillips, 1984).

Como este trabajo se ocupa de la accesibilidad potencial, las estimaciones y análisis se apoyan en datos de la capacidad del servicio que se ofrece (la magnitud de la oferta), de la magnitud de la demanda (información referente al grupo de población en cuestión), y de la localización espacial tanto de la oferta como de la demanda, para considerar los costos de transporte entre los orígenes (las zonas de la ciudad donde radican los usuarios) y los destinos (los sitios de la ciudad donde se localizan las unidades de servicio) (Knox, 1978; Handy, 1993; Verroen y Hilbers, 1996).

Normalmente, los propósitos de la estimación de la accesibilidad son: vigilar que se mantenga un cierto nivel de accesibilidad mínimo aceptable para los usuarios, reducir las desigualdades de accesibilidad entre las diferentes áreas de la ciudad, identificar problemas de accesibilidad que enfrentan las unidades de servicio y que afectan su desempeño, e incluso simular escenarios para evaluar opciones de localización para nuevas unidades de salud. Es menos común que se intenten explicar los niveles de accesibilidad (Goodman et al., 2001) y que se explore la influencia de la accesibilidad en el bienestar de la población

\footnotetext{
${ }^{7}$ En el caso de los servicios de salud, para los cuales se probará el índice de accesibilidad que se propone más adelante, se han identificado algunos factores importantes que afectan la accesibilidad social (y por lo tanto la utilización suficiente y oportuna) de clínicas y hospitales. Factores asociados con las unidades de salud son, por ejemplo, el horario de trabajo, la calidad de los servicios, los métodos de atención, el género del personal, las prácticas médicas y el costo de la atención y los medicamentos; y por el lado de los usuarios destacan, entre otros, su clase social, ingreso, educación, valores culturales, edad, género, percepciones, expectativas y creencias (Garrocho, 1995).
} 
(Gulliford, 2002), en la utilización de los servicios (Meden et al., 2002) o en el éxito de su provisón (Fortney et al., 1999).

\subsection{Principales métodos de estimación de indicadores de accesibilidad}

Los indicadores de accesibilidad que reporta la literatura pueden clasificarse en cinco categorías: de separación espacial, de oportunidades acumulativas, de interacción espacial, de utilidad y espacio-temporales. Salvo los indicadores del primer tipo, todos comparten al menos dos elementos básicos: los costos de transporte (como quiera que sean medidos) entre los orígenes y los destinos, y la magnitud de la oferta del servicio; pero pueden incluir muchas más variables relacionadas de maneras complejas y sofisticadas, de acuerdo con los propósitos de cada análisis. En los siguientes párrafos se hace una apretada revisión de esos indicadores con el fin de estar en condiciones de evaluarlos y de seleccionar, sobre bases informadas, el que mejor se ajuste a las tareas de planeación urbana que se realizan en el país.

\subsubsection{Indicadores de separación espacial}

El indicador de accesibilidad más sencillo es el de separación espacial. La única variable que utiliza es la distancia que separa al origen del destino y un parámetro que representa la fricción de la distancia. ${ }^{8}$ En su forma más general, este indicador estima el promedio de recorridos de todas las zonas de origen a todos los puntos de destino, de la siguiente manera:

$$
A i=\frac{\sum_{j} d i j}{b}
$$

Donde $A i$ es el indicador de accesibilidad, dij es el indicador de los costos de transporte, y $b$ es el parámetro de la fricción de la distancia. Algunos ejemplos de aplicación de este indicador se pueden ver en Dupuy y Stransky (1996), Pooler (1995) y Cervero et al. (1999). Las principales limitaciones del método de separación espacial es que sólo considera la localización relativa de la oferta y la demanda, pero no sus características (magnitud, disponibilidad, tipo de usuario...).

\footnotetext{
${ }^{8}$ Es decir, la sensibilidad de la demanda ante cambios en los costos de transporte.
} 


\subsubsection{Indicadores de oportunidades acumulativas}

El método de oportunidades acumulativas también es muy sencillo. Simplemente define un tiempo de transporte o umbral de distancia para cada origen, y utiliza el número de destinos potenciales dentro de ese umbral como una medida de accesibilidad. La expresión genérica de este indicador es:

$$
A i=\sum_{t} O t
$$

Donde $t$ es el umbral, y $\mathrm{O} t$ es un destino que está dentro del umbral. La única información requerida es la localización de todos los destinos (unidades de servicio) que están dentro del umbral establecido. ${ }^{9}$ Las críticas más fuertes a este método son que no considera ni las características de los usuarios ni su conducta espacial, y que todas las oportunidades localizadas dentro de los límites del umbral son consideradas igualmente accesibles (Voges y Naudé, 1983).

\subsubsection{Indicadores de interacción espacial}

Los indicadores de interacción espacial son mucho más sofisticados que los anteriores, porque incluyen la dimensión de la oferta (como factor de atracción) y los costos de transporte. Esos costos adoptan una medida continua (a diferencia del método de oportunidades acumulativas, que usa un umbral discreto) de tal manera que es sensible a cualquier variación en los costos de transporte. La forma general del modelo es la siguiente:

$$
A i=\sum_{j} \frac{O j}{d_{i j}^{b}}
$$

Donde $A i$ es el indicador de accesibilidad, $O j$ es la atractividad de la unidad de servicio, dij es el costo de transporte entre el origen y el destino, y $b$ es la fricción de la distancia derivada del comportamiento espacial de los usuarios. ${ }^{10}$ Los aspectos más delicados para

\footnotetext{
${ }^{9}$ Algunos ejemplos de aplicación de este indicador se pueden encontrar en las obras de Ikharta y Michell (1997) y Handy (1993).

${ }^{10}$ Nótese que los indicadores de oportunidades acumulativas son un caso especial de indicador de interacción espacial: cuando el parámetro de la fricción de la distancia es igual a cero (Bhat et al., 2000).
} 
poner en operación este indicador son la determinación de las variables que realmente miden la atractividad de las unidades de servicio (usualmente, la dimensión de la oferta), la manera de medir los costos de transporte (tiempo, costo, distancia, energía... los cuales se pueden mezclar para generar un indicador de costo más representativo, y que se pueden medir en términos objetivos o subjetivos), y la forma de la función que representa la fricción de la distancia (exponencial, gausiana....). ${ }^{11}$ La literatura reporta numerosas aplicaciones de indicadores de accesibilidad basados en los razonamientos de la interacción espacial, que incluyen características de la demanda, de la oferta, de la zona de estudio o del sistema de transporte, entre muchas otras. ${ }^{12}$

Aunque los indicadores de accesibilidad del tipo de interacción espacial han mostrado tener un gran potencial analítico y operativo, no están exentos de limitaciones. Las principales críticas que se les hacen es que consideran iguales a todos los individuos de un cierto grupo de población (los individuos localizados en una determinada área de la ciudad), lo que implica que no se podrán encontrar diferentes niveles de accesibilidad entre individuos que residan en la misma zona. Sin embargo, esta crítica aplica a cualquier indicador de accesibilidad que utilice datos agregados a escala de zona (Handy y Niemeier, 1997). Otra crítica se refiere al método de calibración del parámetro de la fricción de la distancia, porque algunos investigadores utilizan valores de parámetros estimados en otras áreas de estudio o para otro tipo de servicios. No obstante, esta crítica se minimiza si se dispone de datos de utilización del servicio en la zona de estudio en cuestión. ${ }^{13}$ Una crítica más que se le hace a este tipo de indicadores es que el resultado se ve afectado de manera igual ante cambios iguales en la atracción o en los costos de transporte, pero esto sólo ocurre con los indicadores más sencillos de tipo gravitacional, pero no con los de interacción espacial (Bhat et al., 2000).

${ }^{11}$ Se puede ver una amplia revisión de estos aspectos en Garrocho y Campos (2005), y Garrocho, Chávez y Álvarez (2003).

12 Algunos ejemplos son: Zhang et al. (1998), Cervero et al. (1999); Bath et al. (2000), y Agyemang-Duah y Hall (1997). Aunque no se deberían de subestimar, sólo por su año de publicación, referencias clásicas tan esclarecedoras como Ingram (1971) o, muy especialmente, Knox (1978), entre otras.

${ }^{13}$ En este sentido, el AmT es afortunada, porque dispone de diversas estimaciones de parámetros de la fricción de la distancia para servicios diversos: desde servicios de consumo cotidiano (tortillerías, panaderías..) hasta bibliotecas públicas, unidades de salud (incluyendo hospitales de especialidades), supermercados e hipermercados (Garrocho, Chávez y Álvarez, 2003). 


\subsubsection{Indicadores de utilidad}

Otro método de estimar la accesibilidad es el que se basa en el concepto de la utilidad derivado de la microeconomía. ${ }^{14}$ Este tipo de indicador se basa en la utilidad individual percibida que reportará cada unidad de servicio (destino) a cada usuario. La forma más general de este indicador es:

$$
A n=E\left[\begin{array}{l}
\operatorname{Max} U j n \\
j \in C
\end{array}\right]=\ln \sum_{j \in C} \exp (V j n)
$$

Esto es, que para un individuo $n$, la accesibilidad es definida como el valor esperado de la utilidad máxima entre todas las alternativas de destino $j$ en el grupo de destinos C. Los indicadores de utilidad han generado mucho interés en el medio académico, especialmente entre los especialistas del transporte. ${ }^{15}$ Las principales críticas a este tipo de indicador son que no todos los destinos están disponibles para todos los individuos, que por lo regular no se integran restricciones a la elección de destinos, y que los resultados son derivados del comportamiento observado de los usuarios (el cual puede estar sujeto a innumerables limitaciones) y que no reflejan con claridad los beneficios de incrementar las opciones de destino (Bath et al., 2000).

\subsubsection{Indicadores espacio-temporales}

Finalmente, el último enfoque que se presenta en esta revisión es el espacio-temporal. Los indicadores espacio-temporales toman como elemento central en la estimación de la accesibilidad, las restricciones temporales de los individuos considerados en el análisis (los usuarios potenciales de los servicios). ${ }^{16} \mathrm{El}$ fundamento de este enfoque es el reconocimiento de que los individuos tienen periodos limitados para realizar determinadas actividades o proyectos (como, por ejemplo, asistir a unidades de servicios). Así, por ejemplo, conforme el tiempo de transporte se incremen-

\footnotetext{
${ }^{14}$ Estos indicadores se reportan en la literatura anglosajona como utility measures of accessibility.

${ }^{15}$ Entre otras aplicaciones de este tipo de indicador, destacan la de Niemeier (1997), Sweet (1997) y Martínez (1995).

${ }^{16}$ La referencia obligada, clásica y no superada, es Hägerstrand (1970). Siempre vale la pena mencionar el título de su brillante artículo: "What about People in Regional Science?".
} 
ta, el tiempo para realizar las actividades se reduce. A su vez, la realización de esas actividades o proyectos enfrenta tres restricciones fundamentales: restricciones de capacidad (relacionadas con las limitaciones del desempeño humano; por ejemplo: los individuos necesitan tiempo para descansar, dormir o comer, y las limitaciones son diferentes entre los individuos, por ejemplo entre un adulto joven y un adulto mayor), restricciones de sincronía (cuando un individuo necesita estar en un sitio específico y en un momento determinado para producir, comerciar o consumir; por ejemplo, en el trabajo, o en las horas de trabajo de las unidades de servicio), y las restricciones de autoridad (las que se derivan de los mandatos superiores, legales, normativos o reglamentarios, que inhiben el movimiento o las actividades; por ejemplo, las condiciones de acceso a las unidades de servicio o las normas de conducta aprobadas).

Las principales críticas que se le hacen al enfoque espacio-temporal es que requiere una aproximación casi individualizada, lo que dificulta instrumentar análisis a escala agregada (grupos de población, áreas intraurbanas, ciudades, zonas metropolitanas...), y por ello la mayoría de los análisis empíricos basados en este enfoque son de corte ilustrativo y confinados a microescalas, de muy corto plazo y esencialmente individual ${ }^{17}$ (Bath et al., 2000; Johnston et al., 2000), aunque en los últimos años han aparecido aplicaciones tecnológicamente muy avanzadas de este enfoque para medir la accesibilidad en ciudades y regiones (Kwan, 1998; Miller, 1999; Lee y McNally, 1998; Wang y Timmermans, 1996).

\subsection{Valoración de los métodos de estimación}

La variedad de indicadores de accesibilidad ha motivado a diversos investigadores a comparar los resultados que se obtienen con cada uno de ellos, con el fin de elegir el más consistente y preciso. Sin embargo, los resultados de esas comparaciones no son concluyentes. Algunos autores advierten que los resultados pueden diferir notablemente según el indicador que se utilice (Guy, 1983), por lo que lo más recomendable es que la situación y el propósito del análisis definan el tipo de indicador que se seleccione (Handy y Neimeier, 1997).

${ }^{17}$ Un ejemplo de análisis de este tipo para la región del valle de Toluca es el de Garrocho (1993a). 
Sin embargo, las diferencias entre los resultados parecen disminuir cuando se trabaja con indicadores derivados de un mismo método. Por ejemplo, Cliff M. Guy (1983) encontró correlaciones altas entre los resultados de diferentes indicadores de interacción espacial, y J. G. Koening (1980) encontró lo mismo para indicadores de utilidad. Uno de los estudios comprensivos más ambiciosos de indicadores de accesibilidad es el que realizó Mei-Po Kwan (1998), en el que compara 12 indicadores de interacción espacial, seis de oportunidades acumulativas y 12 del tipo espacio-temporal, encontrando fuertes correlaciones entre los indicadores de cada categoría, correlaciones altas entre los de interacción espacial y los de oportunidades acumulativas, y correlaciones pobres entre estos dos tipos de indicador y los espacio-temporales. Por su parte, Shunfeng Song (1996) usa nueve diferentes indicadores de accesibilidad para explicar patrones de densidad de población urbana, encontrando que los de interacción espacial tienen un mayor poder explicativo.

Una primera conclusión de la revisión de la literatura es que todos los indicadores de accesibilidad tienen bondades y limitaciones, y que diferentes factores, entre los que destacan el propósito del análisis, la disponibilidad de información, de tecnología y de capacidades técnicas, definirán la selección del tipo de indicador más adecuado para cada situación.

Adicionalmente, en los últimos 10 años la literatura registra una gran diversidad de aplicaciones de indicadores de accesibilidad, muchas de ellas realizadas en ambientes de sistemas de información geográfica (SIG). Las experiencias demuestran que esto reduce los tiempos de cálculo, agiliza la representación cartográfica de los resultados y facilita los análisis (Hardcastle y Cleeve, 1995; Hillman y Pool, 1997). Todo indica que el manejo de indicadores de accesibilidad en ambiente SIG es una veta de investigación aplicada altamente recomendable para la mejor planeación de las ciudades y sus servicios.

En este trabajo se propone un indicador derivado de la interacción espacial en ambiente SIG, debido a la consistencia de los resultados de este tipo de indicador (que muestran correlaciones significativas sin importar el indicador de interacción que se utilice; Kwan, 1998), a su enfoque sistémico (que permite considerar simultáneamente la totalidad de los orígenes, los destinos y los costos de transporte; Drezner y Hamacher, 2001), a su capacidad de explicar diversos procesos urbanos (Song, 1996), a que permite considerar la magnitud y localización espacial de la ofer- 
ta y la demanda según su tipo, así como los costos de transporte medidos de diversas formas (Birkin et al., 2002); a su capacidad para simular escenarios de accesibilidad y utilización de servicios a escala intraurbana y metropolitana (Ghosh y McLafferty, 1987); a la solidez de sus fundamentos conceptuales (Wilson, 1971), y a la facilidad de interpretar sus resultados (TDM, 2003). ${ }^{18}$ Pero, además, y no menos importante, porque se ajusta más a las capacidades técnicas y operativas de las unidades de planeación urbana del país y a las posibilidades de insertarlo en los observatorios urbanos que actualmente se construyen en México.

\section{3. Índice de accesibilidad: diseño y evaluación}

El diseño del índice de accesibilidad del tipo de interacción espacial que se utiliza en este trabajo tiene, en lo general, antecedentes diversos que se reportan en la literatura, ${ }^{19}$ pero responde a los propósitos específicos de este trabajo. Como todos los indicadores de accesibilidad de este tipo, combina un elemento de disponibilidad con otro que representa los costos de transporte que enfrenta la demanda para entrar en contacto con la oferta del servicio, más un parámetro ${ }^{20}$ que representa qué tan sensible es la demanda ante los cambios en los costos de transporte. Su expresión formal es la siguiente:

$$
I i=\sum_{j}\left(\frac{S j}{O t o t}\right) C i j^{-b}
$$

Donde:

Sj = La oferta del servicio en la unidad de servicio " $j$ ”.

Otot $=$ La población demandante del servicio en la zona de estudio.

Cij = Costos de transporte entre el origen " $i$ " (cada subzona residencial donde se localiza la población objetivo) y la unidad de servicio (destino) " $j$ ”.

${ }_{18}$ Adicionalmente a todas estas consideraciones de orden conceptual, también existen dos importantes razones de tipo práctico: la información disponible en el AMT y la experiencia acumulada del equipo de investigación en este tipo de indicadores (Garrocho, 2004).

${ }^{19}$ Desde Knox (1978), hasta los desarrollos más recientes de Luo y Wang (2003), Luo (2004) y Guagliardo (2004).

${ }^{20}$ Llamado de la fricción de los costos de transporte o, más generalmente, de la fricción de la distancia. 
$-b=$ Parámetro de la fricción de la distancia.

Así, la expresión Sj / Otot es un indicador de disponibilidad $a$ espacial, muy utilizado, incluso por organismos internacionales, cuando se analiza la provisión de servicios en áreas urbanas o en regiones, y no es otra cosa más que un indicador de servicios disponibles per cápita en la zona de estudio. En este caso, este cociente indica, de manera muy gruesa, la cantidad de servicios que le correspondería a cada persona del grupo objetivo en toda la zona de estudio, sin importar su localización dentro de la ciudad y en un contexto en el que los costos de transporte fueran irrelevantes. Pero como no lo son, y menos cuando los servicios se ofrecen de manera gratuita o con un precio de casi cero (ya que entonces los costos de transporte actúan como la barrera principal que impide a la población el acceso instantáneo a las unidades de servicio), este componente de disponibilidad es ponderado por el efecto de los costos de transporte (Cij) entre cada subzona residencial de la ZMT donde se localiza la población objetivo (en este caso, cada AGEB donde se localiza población mayor de 65 años sin servicios de seguridad social) y cada una de las unidades de servicio disponibles en la ciudad. Cabe destacar que, a su vez, los costos de transporte son matizados por el parámetro - $b$ (la llamada fricción de la distancia), el cual se estima empíricamente mediante el análisis de datos de utilización del servicio, por lo que sintetiza la sensibilidad de los usuarios ante cambios en los costos de transporte. De esta manera se pueden obtener índices de accesibilidad para cada subzona (AGEB) donde reside población objetivo y para la zona de estudio en su conjunto (en este caso, la ZMT; véanse detalles y ejemplos de aplicación en el Anexo).

Por otro lado, si se le cambia al índice de accesibilidad el subíndice de la sumatoria, se puede estimar la accesibilidad desde el punto de vista de la oferta y comparar la accesibilidad entre unidades de servicio, identificar las menos accesibles y proceder a analizar las causas. Éste sería un indicador del desempeño del servicio, que se expresaría de la siguiente forma: ${ }^{21}$

$$
I j=\sum_{i}\left(\frac{S j}{\text { Otot }}\right) C i j^{-b}
$$

${ }^{21}$ Véanse detalles y ejemplos de aplicación en el Anexo. 
Por lo tanto, el índice de accesibilidad (en su forma tanto de demanda como de oferta) está diseñado de tal manera que es sensible a cambios en:

- La dimensión de la oferta y la demanda del servicio (“Sj” y "Otot", respectivamente).22

- La relación entre oferta y demanda (Sj / Otot).

- Los costos de transporte entre orígenes y destinos (Cij). ${ }^{23}$

- La sensibilidad de los usuarios ante cambios en los costos de transporte “- $b$ ". ${ }^{24}$

Adicionalmente, el índice tiene otras ventajas. Si se proyectan hacia el futuro los valores de las variables (de alguna o de todas, según sean las condiciones que se quieran simular), se pueden generar escenarios probables de accesibilidad a los servicios, lo que permitiría evaluar las opciones de localización de nuevas unidades de servicio, y también facilita hacer comparaciones en materia de accesibilidad entre áreas intraurbanas de una misma ciudad. Esto es particularmente importante si se considera a la accesibilidad como un indicador de calidad urbana (bienestar), como se hace en este trabajo.

\subsection{Evaluación del índice de accesibilidad: consistencia y principales limitaciones}

Una complicación inherente al proceso de diseñar indicadores de accesibilidad es evaluar la calidad del diseño. Para esto, diversos autores han propuesto algunos criterios básicos que debe cumplir cualquier indicador de accesibilidad, pero las referencias más citadas en la literatura, a pesar de tener más de 25 años de haber sido publicadas, siguen siendo las de Jörgen W. Weibull (1976) y J. M. Morris et al. (1979), quienes proponen los siguientes criterios de garantía de consistencia:

22 Por ejemplo, si se abren o cierran unidades de servicio, o si se amplía o reduce su capacidad de atención, o si suben o bajan las tasas de crecimiento de la población objetivo, o si aumenta o se reduce la población en áreas específicas de la ciudad.

${ }^{23}$ Y, por lo tanto, el índice es sensible a los cambios de localización de las unidades de servicio y del patrón espacial de la demanda, lo cual es particularmente importante si se analizan ciertos grupos de población (Garrocho y Campos, 2005). Cabe recordar que los costos de transporte se pueden estimar en unidades diversas, aunque en este trabajo se utilizaron solamente unidades de distancia.

${ }^{24}$ Éste es un componente conductual que se estima a partir de los registros de utilización del servicio (Rosenberg y Everitt, 2001). 
- El orden en el que se consideren los datos de los orígenes y los destinos no debe afectar el indicador.

- El indicador no debe aumentar al incrementarse los costos de transporte, ni reducirse al aumentar la magnitud de la oferta.

- El indicador debe considerar el comportamiento espacial de los usuarios.

- El indicador debe ser viable en términos operativos y no ser sólo un ejercicio académico.

- Los resultados del indicador deben ser fáciles de entender e interpretar.

Actualmente, estos criterios siguen siendo los referentes fundamentales para el diseño de indicadores de accesibilidad (Bath et al., 2000). Las pruebas que se realizaron muestran que el índice de accesibilidad que aquí se propone cumple con todas las especificaciones de Weibull y Morris et al., tal y como se puede comprobar revisando el Anexo.

Es claro que las opciones de aplicación del índice de accesibilidad que se diseña en este trabajo son múltiples. Sin embargo, se debe ser cauteloso al utilizarlo, ya que, como cualquier instrumento, tiene limitaciones que se deben tener en mente para analizar con mayor justeza sus resultados. Dos son las más importantes. La primera, que considera homogéneas la oferta y la demanda; es decir, no considera aspectos cualitativos importantes que afectan la calidad de los servicios, ni los aspectos que marcan la diferencia entre un usuario y otro, como, por ejemplo, el estado físico de las personas, su género, grado de movilidad, apoyos familiares o disponibilidad de tiempo o medios de transporte, por mencionar sólo algunos. ${ }^{25}$ En otras palabras, se trata de un indicador de accesibilidad agregado, que poco nos dice de las condiciones particulares de los usuarios y por lo tanto de su accesibilidad individual a los servicios. La segunda limitación importante del índice es que el parámetro $(-b)$ que sintetiza la conducta espacial de los consumidores, se estima a partir de datos efectivos de utilización, ${ }^{26}$ lo que ciertamente refleja el comportamiento espacial de los usuarios, pero no necesariamente un

${ }^{25}$ En Garrocho (1995) se presenta una discusión conceptual muy amplia de todos estos aspectos, así como sobre su influencia en el AMT.

${ }^{26}$ Lo que Joseph y Phillips (1984) llaman accesibilidad revelada. 
patrón deseable, adecuado u óptimo, sino simplemente el que se registra en la realidad. ${ }^{27}$

No obstante, por el momento los interesados en la accesibilidad de servicios se encuentran en una encrucijada donde sólo tienen dos opciones analíticas: o utilizar un indicador de accesibilidad agregado (y al parecer no hay más prácticos que los derivados de la interacción espacial), con lo que pierden la individualidad de los usuarios; o utilizar un indicador desagregado (preferentemente los de utilidad o los espacio-temporales), con lo que aprehenden la individualidad de uno o de unos -muy pocos- usuarios, pero pierden capacidad para diseñar políticas públicas de carácter general (Guagliardo, 2004). Evidentemente, lo mejor sería conjuntar ambos enfoques en una misma estructura analítica, pero hasta el momento no se tiene claro cómo hacerlo (Bath et al., 2000). ${ }^{28}$

\section{Definición operativa del índice de accesibilidad para el AMT}

Con el propósito de probar la capacidad del índice de accesibilidad a unidades de servicio, en este apartado se estima la accesibilidad geográfica de los servicios de salud pública para la población mayor de 65 años en el AMT. ${ }^{29}$ El índice que se presentó en su formulación general en la sección anterior, se instrumenta de la siguiente manera:

${ }^{27}$ Con el fin de ahorrar espacio y ganar claridad, en el Anexo se presenta un ejemplo detallado de aplicación del índice de accesbilidad. Vale más un ejemplo que mil palabras.

${ }^{28}$ Aunque existen propuestas interesantes aplicadas al sistema de transporte, como la de Sweet, 1997.

${ }^{29}$ Uno de esos grupos son los mayores de 65 años, que en el país y en la ciudad constituyen el grupo de más acelerado crecimiento demográfico (Tuirán, 1999; Partida, 2001), y cuyo patrón de localización en el espacio metropolitano de Toluca tiene características muy particulares (Garrocho y Campos, 2005). Junto con los niños y las mujeres embarazadas, los mayores de 65 años son un grupo estratégico de atención para los sistemas de salud. Vulnerables y casi en permanente necesidad de atención preventiva o curativa, los mayores de 65 años -por sus limitaciones físicas- son altamente dependientes de los demás para acceder oportunamente a los servicios médicos. Su falta de movilidad (en ocasiones su discapacidad), más la falta de tiempo de los que los pueden llevar a recibir atención y el esfuerzo y el costo que implica llevar -y traer- a personas mayores para que reciban servicios médicos, explican que con frecuencia los ancianos registren tiempos más largos entre la manifestación de los síntomas de enfermedad y la recepción de atención médica, con lo que sus padecimientos pueden agravarse y hacerse más difíciles de solucionar (Garrocho, 1995). Existe abundante evidencia de que la accesibilidad a los servicios afecta seriamente la calidad y oportunidad de su utilización, lo que influye en los niveles de bienestar de la población (Scarpaci, 1989; Phillips, 1990; Garrocho, 1995). 


$$
I i=\sum_{j}\left(\frac{S j}{O t o t}\right) C i j^{-b}
$$

Donde:

Sj = Capacidad de atención de cada unidad de salud " $j$ ”, estimada a partir de la productividad promedio por médico que ha calculado el Instituto de Salud del Estado de México (28 consultas diarias por médico).

Otot $=$ Población que gana menos de dos salarios mínimos mayor de 65 años y sin seguridad social, de acuerdo con las estimaciones del Instituto de Salud del Estado de México. Este dato se tiene para cada AgEB $(\mathrm{O} i)$ y para la ZMT en su conjunto (Otot).

$\mathrm{C} i j=$ Distancias lineales entre el centroide de cada AGEB (origen) " $i$ " donde radica población objetivo (Oi) y la unidad de salud (destino) " $j$ ”. Tanto el cálculo de los centroides como el de la matriz de distancias lineales origen-destino se calcularon con el sIG Arc View.

$-b=$ Parámetro de la fricción de la distancia estimado a partir de los registros de utilización de las unidades médicas durante 2004. El parámetro para las consultas generales en el AMT fue de 2.99. ${ }^{30}$

Las definiciones operativas de las variables del índice de accesibilidad tienen, aparentemente, algunas limitaciones importantes, especialmente la que se refiere a los costos de transporte, porque se utilizan distancias lineales, pudiéndose haber utilizado algún índice que reflejara mejor los costos en los que incurren los usuarios para acceder a las unidades de salud. ${ }^{31}$ Sin embargo, la sencillez de la definición operativa reporta a cambio la enorme ventaja de que la base de datos necesaria es muy económica, rápida y fácil de construir, ya que se utilizan fuentes de información convencionales (como los censos de población y las

${ }^{30}$ El método de estimación de los parámetros de la fricción de la distancia es algo laborioso pero se presenta un resumen el Anexo. Mayores detalles se pueden ver en Garrocho (1995) y Garrocho et al. (2003).

${ }^{31}$ Aunque disponemos de datos y modelos de transporte para el AMT que permitirían estimar los tiempos de transporte entre los orígenes y las unidades de salud, usar esa información dificultaría hacer comparaciones intermetropolitanas, ya que son pocas ciudades las que tienen información de este tipo para usarla en sus observatorios urbanos. Uno de los mejores ejemplos de indicadores de costos de transporte a unidades de salud lo presenta Whitelegg en su libro clásico de 1982. 
estadísticas que genera el propio sector salud, y rutinas propias de los sistemas de información geográfica). Además, con este nivel de sencillez es suficiente para tener una medida útil de la accesibilidad -en cuanto a su orden de magnitud-de las zonas de la ciudad, de las unidades de salud y del área metropolitana en su conjunto, que hace posible monitorear la evolución de la accesibilidad en el tiempo, hacer comparaciones entre zonas de la ciudad y entre unidades de salud, y simular escenarios de planeación, cuidando siempre que los resultados sean claros y fácilmente entendibles por los administradores urbanos.

\section{Probando el indicador de accesibilidad para el caso de los servicios de salud en el AMT}

\subsection{La distribución espacial de la demanda}

La población pobre mayor de 65 años sin seguridad social en el AMT se concentra en las áreas más antiguas de la ciudad, especialmente en el centro histórico del municipio de Toluca y en los centros históricos de los poblados que en las últimas décadas se han integrado al área metropolitana (figura I). Alrededor de esos centros y subcentros históricos de alta concentración de población mayor, se distinguen zonas (anillos) de concentración intermedia de población mayor de 65 años, y finalmente zonas de baja presencia de ese grupo de población. En síntesis, lo que se observa es una distribución espacial de la población que registra picos de concentración en los centros históricos y en los barrios antiguos, y valles de baja concentración en los puntos intermedios. ${ }^{32}$

\subsection{La distribución espacial de la oferta}

En general, la distribución espacial de las unidades de salud tiene una elevada correspondencia con la distribución espacial de la demanda (figura I). Muestra de esto es que sólo seis de las 44 unidades localizadas en el AMT se ubican en AGEB de baja presencia de población mayor de 65 años. En otras palabras: 86\% de la distribución espacial de la oferta es altamente consistente con la distribución espacial de la demanda. Adicionalmente, los tamaños de las unidades de salud también registran una alta rela(2005).

${ }^{32}$ Como se reporta en el análisis de geografía urbana que hacen Garrocho y Campos 


\section{Figura I}

Población mayor de 65 años no derechohabiente por AGEB, y distribución de la oferta de servicios de salud en el Área Metropolitana de Toluca

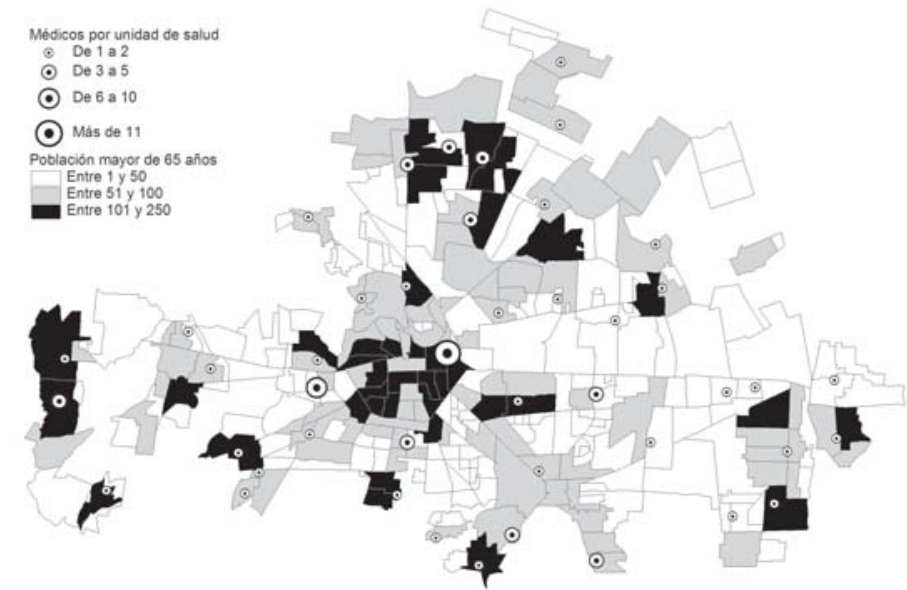

Fuente: INEGI (2002); Instituto de Salud del Estado de México (ISEM) (2004).

ción con las dimensiones de la demanda, particularmente en la parte central, norte y oeste del AMT. Es notable esta correspondencia entre las dimensiones y la distribución espacial de la oferta y la demanda, lo que indica una adecuada respuesta institucional en términos de la distribución territorial de los servicios, lo cual tiene un grado de complejidad mayor en una ciudad de tan rápido crecimiento como el AMT.

\subsection{Accesibilidad por área de la ciudad: calidad urbana}

De acuerdo con la Secretaría de Desarrollo Social, el radio de cobertura normativo de las unidades de salud en áreas urbanas es de un kilómetro (Sedesol, 1999). Al representar en un mapa la cobertura normativa es posible dividir (clasificar) el AMT en zonas cubiertas y no cubiertas por el servicio (figura II). Éste es un buen punto de arranque para analizar la accesibilidad a los servicios de salud, pero no es suficiente. La división dicotómica simple entre zonas cubiertas y zonas no cubiertas es tajante, no distingue grados de accesibilidad y no corresponde plenamente con lo que ocurre en la realidad. ${ }^{33}$ En los hechos, la población que se

\footnotetext{
${ }^{33}$ Aunque existen ejemplos muy interesantes y exitosos de análisis a partir de radios normativos, como el de Harner et al. (2002).
} 


\section{Figura II}

Cobertura normativa de los centros de salud urbanos del Área Metropolitana de Toluca

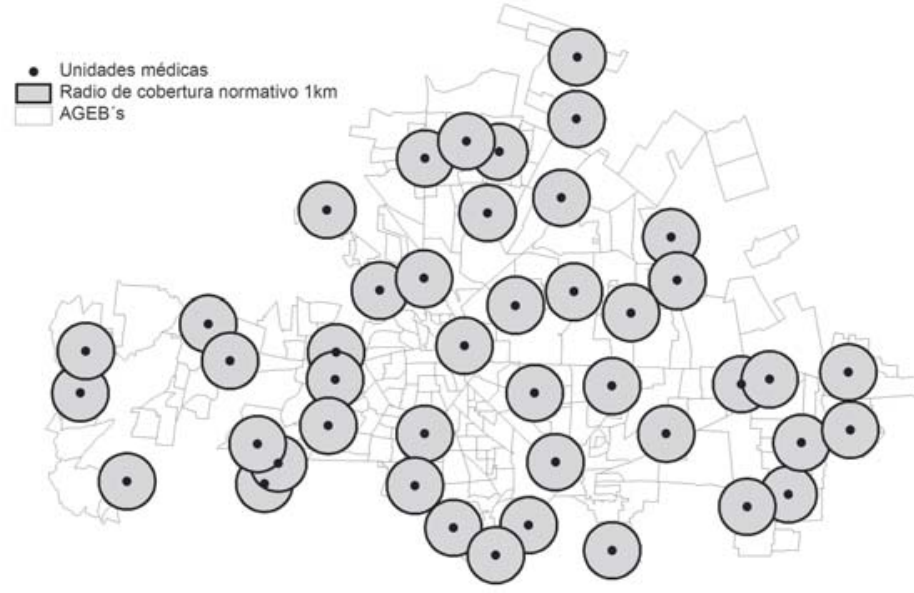

Fuente: INEgr (2002); Instituto de Salud del Estado de México (2004). El valor del radio de cobertura normativo se obtuvo de Sedesol (1999).

\section{Figura III}

Accesibilidad a servicios públicos de salud de la población mayor de 65 años no derechohabiente por AGEB del Área Metropolitana de Toluca

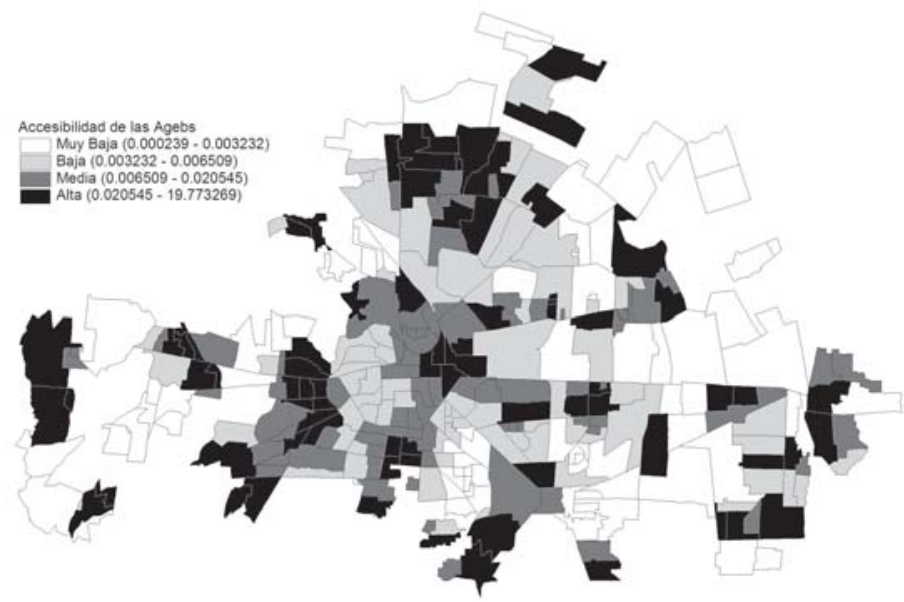

Fuente: INEGI (2002); Instituto de Salud del Estado de México (ISEM) (2004). 
localiza en las zonas no cubiertas en términos normativos, sí tiene acceso -y en intensidades diferentes- a las unidades de salud en su conjunto, y no sólo a la que se localiza a una cierta distancia normativa. Estas intensidades o niveles de accesibilidad al sistema de salud en su conjunto (como oferta total del servicio o $\mathrm{Sj}$ ) sólo pueden observarse si se calcula un índice de accesibilidad que genere resultados continuos (es decir, una superficie de accesibilidad), en lugar de resultados dicotómicos simples.

Con el cálculo del índice de accesibilidad emergen las diferentes intensidades de accesibilidad potencial a lo largo y ancho del AMT (figura III). Los resultados del índice de accesibilidad muestran un paisaje mucho más realista y complejo que la simple aplicación de radios normativos de cobertura. Así, las áreas de la ciudad donde se localizan las unidades de salud muestran elevados niveles de accesibilidad, las áreas adyacentes registran niveles de accesibilidad intermedios, y las áreas más alejadas de las unidades de salud -consideradas éstas en conjunto, como un verdadero sistemamuestran niveles de accesibilidad bajos o muy bajos.

Las AGEB con los menores niveles de accesibilidad se localizan, en general, en la periferia del AMT, aunque también se detectan, como excepción, algunas AGEB ubicadas en el interior de la ciudad. Esas zonas de baja accesibilidad pueden ser atendidas con la instalación de nuevas unidades o ampliando las unidades existentes más cercanas, y la decisión entre ambas opciones puede ser apoyada mediante la simulación de escenarios utilizándose el índice de accesibilidad que aquí se propone, como se verá más adelante (en la sección 6 de este documento).

El cálculo de la accesibilidad a los servicios de salud a escala de AGEB no sólo permite identificar áreas de la ciudad con problemas críticos de acceso al sistema de salud en su conjunto, que se convierten en objetivos estratégicos para la planeación espacial del sistema de salud, sino también profundizar en el análisis de la desigualdad de acceso, algo que no se puede hacer utilizando solamente los radios normativos de cobertura. Para facilitar el análisis, las AGEB se clasificaron en tres categorías en función de los valores de sus índices de accesibilidad: ganadoras, intermedias y marginadas. Las primeras -las ganadoras- son aquellas que registran niveles de accesibilidad iguales al promedio metropolitano o arriba del promedio. Las segundas -las intermedias-incluyen 66\% de las AGEB con accesibilidad menor al promedio metropolitano, pero que son las más próximas al promedio; y las terceras -las 


\section{Figura IV}

Desigualdad de acceso de la población residente en las AGEB a las unidades de salud de primer nivel del Área Metropolitana de Toluca

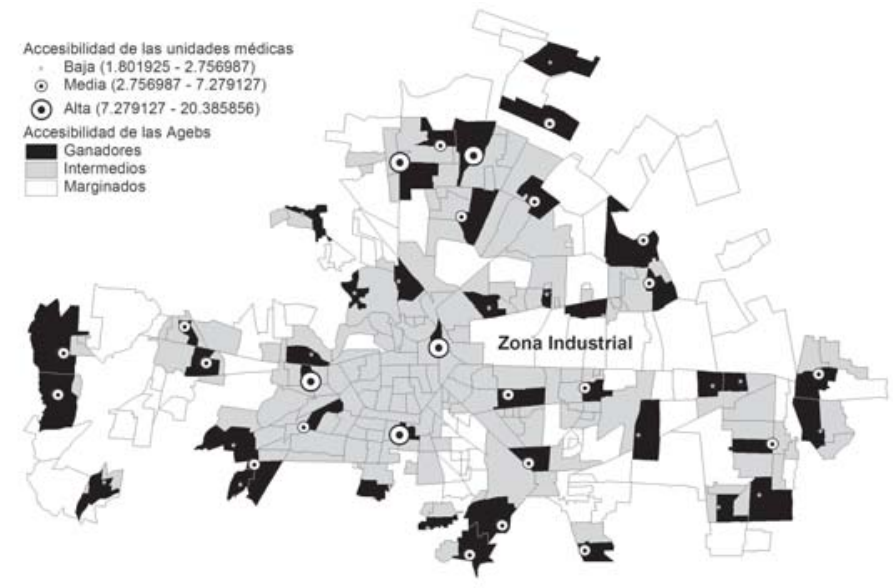

Fuente: INEGI (2002); Instituto de Salud del Estado de México (ISEM) (2004).

marginadas - son las AGEB con los niveles más bajos de accesibilidad: $33 \%$ más alejado del promedio metropolitano (figura IV). ${ }^{34}$

Las AGEB ganadoras suman 45 (20.6\%) y albergan a 6,903 mayores de 65 años, pobres y sin seguridad social, que representan $21 \%$ del total de la población objetivo. Las AGEB intermedias son 172 (59.9\%), donde se localizan 20,079 habitantes que equivalen a $61 \%$ de la población objetivo; y la población localizada en las AGEB marginadas ( 87 en total) equivale a $19.8 \%$ del total (es decir, 6,526 habitantes). En total, casi $80 \%$ del total de la población objetivo está por debajo de la media del nivel de accesibilidad.

La diferencia entre los recorridos mínimos necesarios para acceder a la unidad de salud más próxima también nos da una medida de desigualdad de acceso en el AMT. Mientras el recorrido mínimo necesario promedio es 1.08 kilómetros (8\% arriba de lo que marca el radio de cobertura normativa), el recorrido mínimo necesario para la población de las AGEB con mayor accesibilidad es de 0.12 kilómetros (que se registra en una de las AGEB de menor tamaño donde se localiza una unidad de salud), y el recorrido mínimo necesario más elevado es el de una AGEB localizada en la periferia

${ }^{34}$ Esta clasificación es mucho más útil que la de zonas servidas y zonas no servidas que se obtiene cuando se utilizan radios normativos de cobertura de servicios. 


\section{Figura $v$}

Accesibilidad de fin de semana de la población residente en las AGEB y de las unidades de salud de primer nivel de Área Metropolitana de Toluca

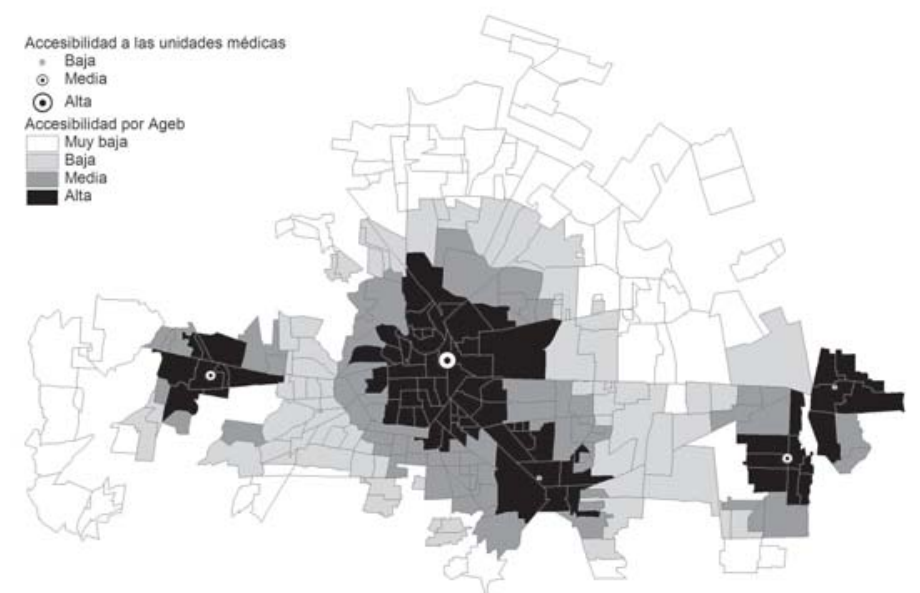

Fuente: INEGI (2002); Instituto de Salud del Estado de México (ISEM) (2004).

del oeste del AMT, cuya población requiere recorrer 4.3 kilómetros para acceder a la unidad de salud más cercana. Es decir, casi cuatro veces más que el promedio metropolitano y 35 veces más que la población localizada en las AGEB mejor posicionadas.

Por su parte, las desigualdades en accesibilidad a los servicios médicos durante los fines de semana (cuando cierran 90\% de las unidades de salud) son mucho mayores (figura v). Todos estos datos dan una idea de la discriminación espacial que se registra en el AMT, en términos de la accesibilidad a unidades de salud para población pobre mayor de 65 años sin seguridad social.

\subsection{Accesibilidad por unidad de salud: desempeño urbano}

El índice de accesibilidad de las unidades de salud es resultado de la interrelación entre los costos de transporte que deben sufragar los usuarios para acceder al servicio y la magnitud de la oferta en el punto de atención. Esto se refleja en la distribución de los índices de accesibilidad por unidad de salud (figura vi). Las unidades con mayor capacidad de atención y mejor ubicadas respecto a la demanda registran los índices de accesibilidad más altos. Destacan, lógicamente, las localizadas en el centro del AMT y las que se localizan en las partes más consolidadas de la ciudad. 


\section{Figura VI}

Accesibilidad de las unidades de salud de primer nivel del Área Metropolitana de Toluca

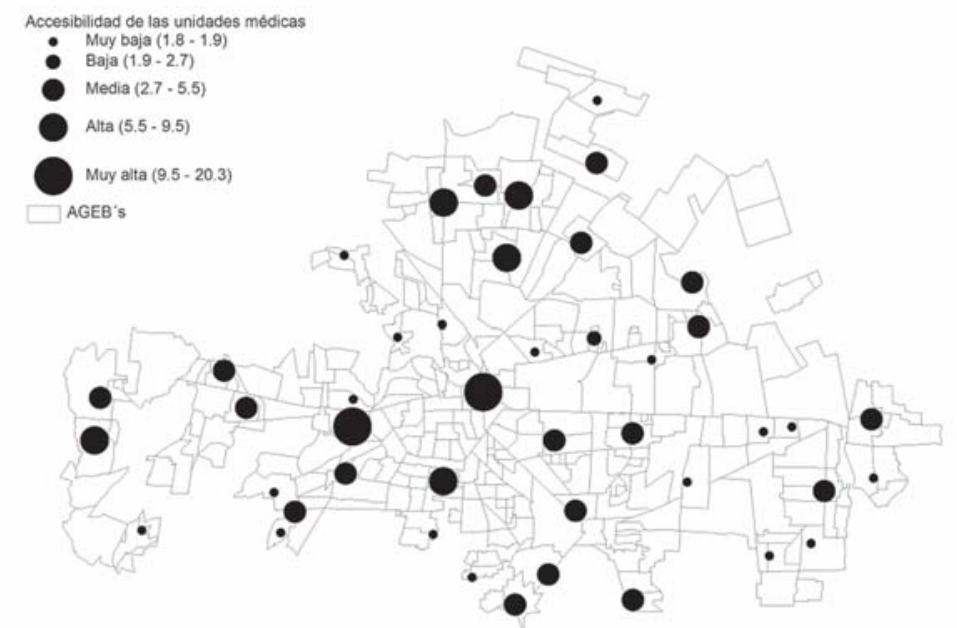

Fuente: INEgi (2002); Instituto de Salud del Estado de México (ISEM) (2004).

Por su parte, las unidades que resultan con los índices de accesibilidad más bajos son aquellas con poca capacidad de atención y localizadas en la periferia del AMT, pero que cumplen con su función de ofrecer atención a zonas de baja concentración de demanda. Esto refleja la correspondencia que ya se anticipaba entre la distribución espacial de la demanda y la de la oferta, pero además, la correspondencia espacial entre la dimensión de la demanda y la respuesta institucional.

Sin embargo, se detectan cuatro unidades de salud que registran bajos niveles de accesibilidad a pesar de que no se localizan en la periferia del AMT, por lo que vale la pena analizar más a fondo estos casos. Una de esas unidades se localiza en el borde norte del centro histórico del AMT, otra al este de la unidad anterior, y las dos restantes al oeste de la mancha urbana (figura vI). Como se puede observar, a pesar de que esas cuatro unidades se ubican al interior del AMT, y por lo tanto ganan en proximidad con la población objetivo, su baja capacidad de atención contrarresta sus ventajas de localización, además de que las dos unidades localizadas más al oeste están en el límite de la zona industrial, lo que también explica de manera lógica su baja accesibilidad. De cualquier manera, esas unidades cuya capacidad de atención no concuerda plenamente con la distribución espacial y con las 
dimensiones de la demanda, representan apenas 9\% del total de las unidades de salud que operan en el AMT.

\subsection{Accesibilidad metropolitana}

La sumatoria de los índices de accesibilidad de todas las AGEB que integran el AMT equivale a lo que aquí llamamos accesibilidad metropolitana, y sirve de referente para monitorear en el tiempo la accesibilidad total del sistema de salud, para evaluar decisiones de planeación y para hacer comparaciones con lo que ocurre en otras ciudades. Para el caso del AMT, la accesibilidad metropolitana fue de 186.7 (indicador que debería subir a lo largo del tiempo, si la planeación del sistema de salud es exitosa), la accesibilidad promedio por AGEB fue de 0.61 (indicador que también debería subir), y la desviación estándar fue de 1.98 (como este indicador refleja la desigualdad de acceso, debería descender en el tiempo).

\section{Simulación de escenarios: el indicador de accesibilidad como instrumento de planeación}

La construcción de escenarios permite simular los posibles efectos de una cierta acción de política pública en el desempeño de la ciudad y/o de los servicios (de salud), en términos de su accesibilidad y, por lo tanto, del beneficio que reportan a la población objetivo (la población de la tercera edad). Con fines ilustrativos de la utilidad del índice de accesibilidad aquí propuesto, se decidió evaluar los efectos de dos posibles acciones de política pública:

$i$. Instalar una nueva unidad de servicio al este del AMT, donde se padecen bajos niveles de accesibilidad a los servicios de salud.

ii. Incrementar el número de médicos en una unidad ya establecida en la misma zona del AMT.

La simulación de los escenarios permitiría evaluar y elegir cuál de las acciones de política pública generaría un mayor impacto en términos de la accesibilidad a los servicios de salud por parte de la población de la tercera edad que reside en la zona adyacente al sitio donde se planea incrementar la oferta del servicio, $y$ cuál acción tendría mayor impacto en la accesibilidad global metropolitana (figura VII). 


\section{Figura VII}

Localización de la zona evaluada en los escenarios 1 y 2 para medir la accesibilidad de la población residente en las AGEB y de las unidades de salud de primer nivel del Área Metropolitana de Toluca

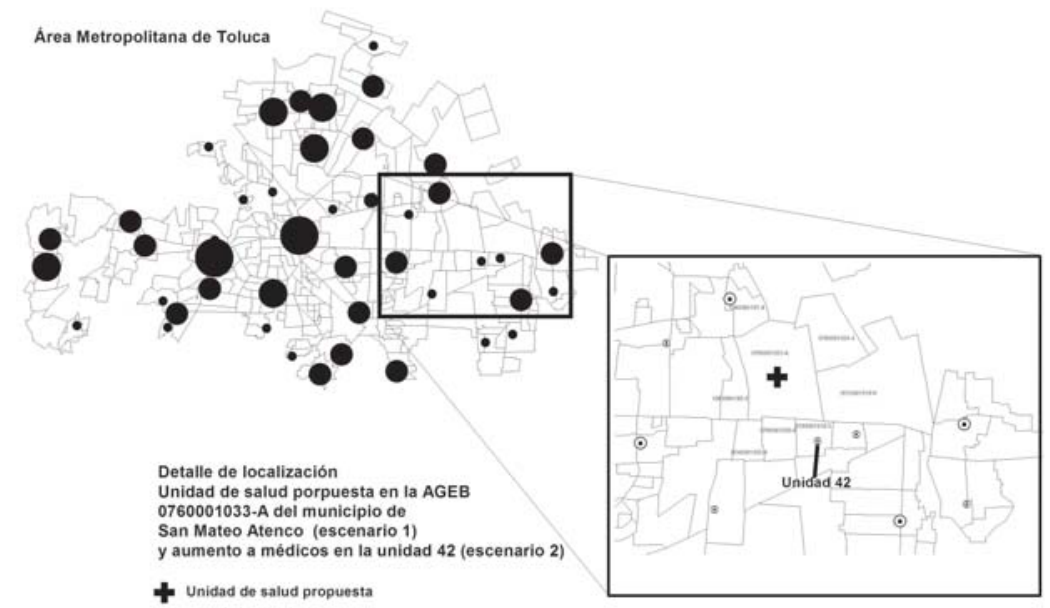

Fuente: INegi (2002); Instituto de Salud del Estado de México (ISEM) (2004).

\subsection{Escenario 1: construcción de una nueva unidad de salud}

Como una alternativa para mejorar la accesibilidad de la parte este del AMT, que se ha identificado como de baja accesibilidad (figura III), se simula la construcción de una nueva unidad de salud localizada en el centro de una de las AGEB más desaventajadas del municipio de San Mateo Atenco. ${ }^{35}$

Esa acción de política pública generaría una nueva superficie de niveles de accesibilidad. Si bien a escala metropolitana el escenario no cambia de manera radical, puesto que la construcción de una sola unidad de salud constituye una acción de baja intensidad, el impacto sí es importante en la zona colindante al sitio donde se simula la construcción de la unidad de salud.

Así, mientras el índice de accesibilidad metropolitana pasa de 186.8 a 188.6, un incremento marginal de apenas de 1.8 puntos,

\footnotetext{
${ }^{35}$ Por supuesto que existen métodos muy sofisticados para decidir la localización de nuevas unidades de servicio (se pueden ver ejemplos de aplicación para la ZMT en Garrocho [1995] y Garrocho et al. [2003]). Sin embargo, el propósito de esta sección es ilustrar cómo una herramienta tan sencilla, como el índice de accesibilidad que se propone en este trabajo, puede ayudar a explorar de manera rápida las implicaciones de localizar nuevas unidades de servicio en la ciudad o ampliar las existentes.
} 
que equivale a menos de uno por ciento, en las AGEB colindantes al lugar donde se simula la construcción de la clínica, el indicador de accesibilidad se eleva 33.3\%. Además, el recorrido mínimo promedio que tendrían que realizar los usuarios de la zona adyacente para acceder a una unidad de salud pasa de 1.5 a 1.0 $\mathrm{km}$, lo que significa una reducción de 33\% en los recorridos mínimos que deberán hacer los mayores de 65 años residentes en la zona para acceder a una unidad de salud (cuadros 1 y 2).

\section{Cuadro 1 \\ Área Metropolitana de Toluca. Escenarios de planeación e indicadores de desempeño}

\begin{tabular}{lrcc}
\hline & Inicial & 3 médicos más & 1 clínica nueva \\
\cline { 2 - 4 } Población beneficiada & 15,223 & 15,223 & 15,223 \\
AGEB en el AMT & 304 & 304 & 304 \\
Accesibilidad en la zona & 186.77 & 192.21 & 188.58 \\
$\begin{array}{l}\text { Impacto respecto a la } \\
\quad \text { situación inicial }\end{array}$ & 0.00 & 5.44 & 1.81 \\
Incremento porcentual & - & 2.91 & 0.97 \\
$\begin{array}{l}\text { Distancia mínima promedio } \\
\text { para acceder a una unidad }\end{array}$ & & & \\
$\quad$ de salud & 1.06 & 1.06 & 1.04 \\
Incremento porcentual & 0.00 & 0.00 & -1.19 \\
\hline
\end{tabular}

\section{Cuadro 2}

Zona este del AMT. Escenarios de planeación e indicadores de desempeño

\begin{tabular}{lrcc}
\hline & Inicial & 3 médicos más & 1 clínica nueva \\
\cline { 2 - 4 } Población beneficiada & 217 & 217 & 217 \\
AGEB en la zona este del AMT & 8 & 8 & 8 \\
Accesibilidad en la zona & 377.74 & 755.79 & 503.77 \\
$\begin{array}{l}\text { Impacto respecto a la } \\
\quad \text { situación inicial }\end{array}$ & 0 & 378.05 & 126.03 \\
$\begin{array}{l}\text { Incremento porcentual } \\
\text { Distancia mínima promedio }\end{array}$ & - & 100.08 & 33.36 \\
$\quad$ para acceder a una unidad \\
$\quad$ de salud
\end{tabular}


Como es lógico, los efectos espaciales de esa acción de política pública se manifiestan con mayor intensidad en las AGEB adyacentes a donde se propone construir la nueva unidad de salud, mientras que en el resto de las AGEB los niveles de accesibilidad permanecen prácticamente sin cambios, debido a que el incremento en la magnitud del servicio es relativamente bajo y no alcanza a revertir la influencia de los costos de transporte en el acceso de la población a los servicios de salud (figura VIII).

\section{Figura VIII}

Escenario 1: accesibilidad a los servicios de salud de la población mayor de 65 años no derechohabiente por AGEB del Área Metropolitana de Toluca

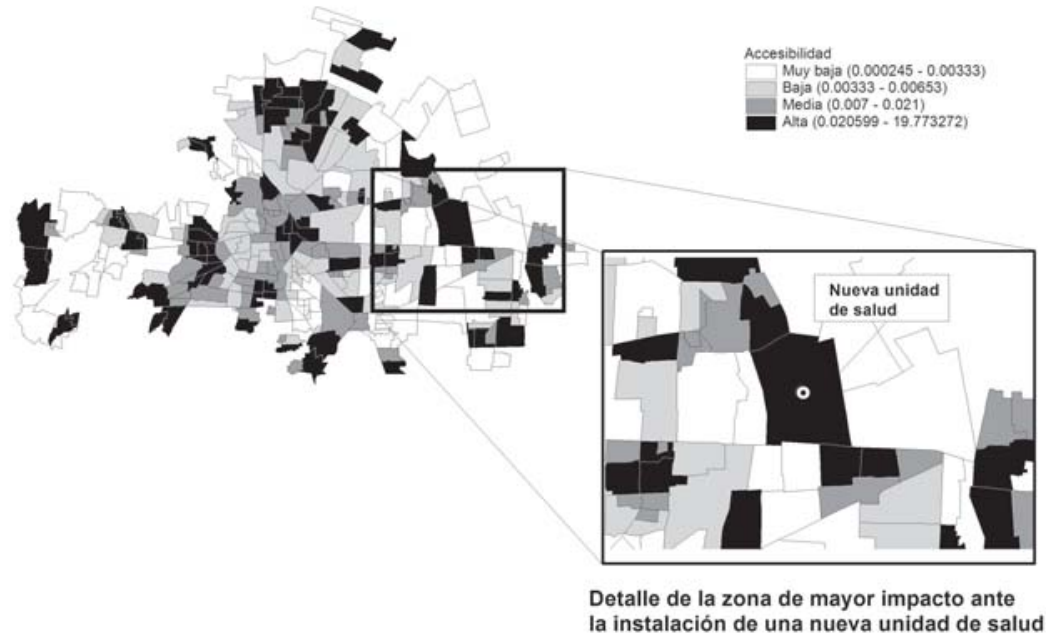

Fuente: INEGI (2002); Instituto de Salud del Estado de México (ISEM) (2004).

\subsection{Escenario 2: ampliación de la planta médica}

El escenario 2 simula la contratación de tres médicos que se ubicarán en una de las unidades existentes al este del AMT. Al comparar los efectos en la accesibilidad derivados de la construcción de una nueva unidad con los que se generarían al incrementar el número de médicos, es claro que es mucho más conveniente la segunda opción.

Por una parte, los niveles de accesibilidad global metropolitana son muy superiores a los derivados de la construcción de una unidad de salud (que contaría con un solo médico), pues el indicador metropolitano se incrementa 5.4 puntos (contra 1.81 del escena- 
rio 1), con lo que se alcanza un índice de accesibilidad global de 194.0 (mientras en el escenario 1 se llegaba a 188.6) (cuadros 1 y 2). Por el otro lado, al analizar los impactos en las AGEB colindantes al sitio donde se propone incrementar la planta de médicos, los beneficios también son mayores que en el escenario 1. El incremento de la accesibilidad que reporta contratar a tres nuevos médicos en una de las clínicas existentes en esa parte del AMT es de $100 \%$ respecto a la situación inicial, y de 50\% respecto al escenario 1 (que simula la construcción de una clínica) (figura IX).

\section{Figura IX}

Escenario 2: accesibilidad a los servicios de salud de la población mayor de 65 años no derechohabiente por AGEB del Área Metropolitana de Toluca

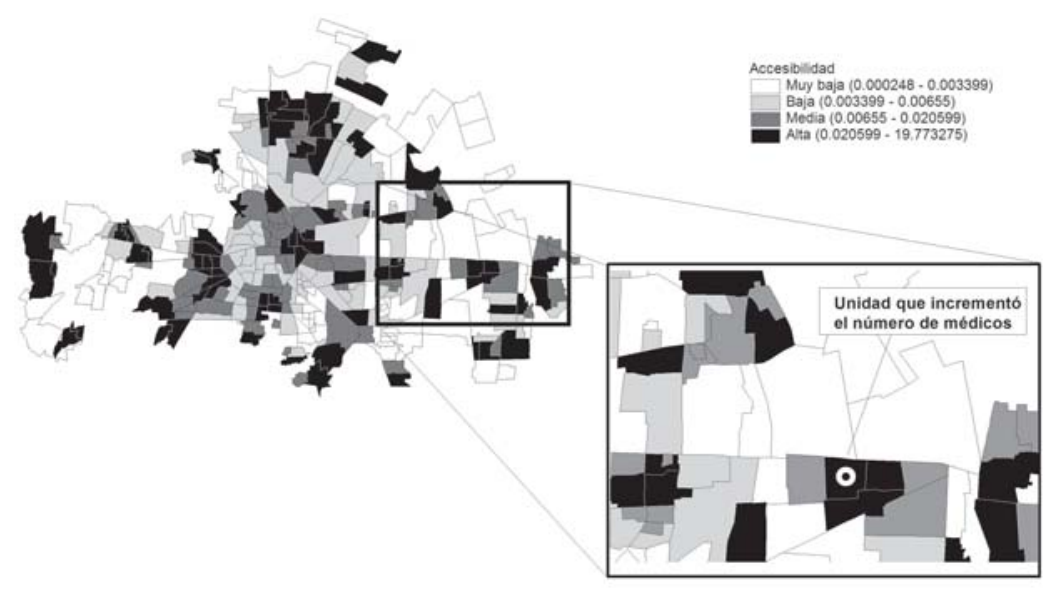

Detalle de la zona de mayor impacto ante la instalación de una nueva unidad de salud

Fuente: INEgi (2002); Instituto de Salud del Estado de México (ISEM) (2004).

\subsection{Recomendaciones de politica derivadas de la} formulación de escenarios

En términos de la accesibilidad de la población objetivo, es mucho más recomendable contratar a tres nuevos médicos en una de las unidades existentes al este del AMT que construir una nueva unidad de salud (que opere con un solo médico), aun si se localiza en la parte menos favorecida de la zona objetivo. De cualquier manera, habría que comparar los requerimientos económicos (costos de inversión y costos de operación) de construir una nueva unidad de salud (terreno, costos de construcción, equi- 
pamiento, la contratación de un médico...) contra los que implica la contratación de tres nuevos médicos en una unidad de salud ya existente en la zona, para completar el análisis. De cualquier manera, el índice de accesibilidad es una herramienta de planeación que facilita concentrarse en el objetivo central de la política pública que pretende facilitar el acceso de la población mayor de 65 años a los servicios de salud.

\section{Conclusiones}

El índice de accesibilidad que se presentó en este trabajo incorpora: i) un indicador de disponibilidad; ponderado por, ii) los costos de transporte que los usuarios deben sufragar para acceder a las unidades de servicio; los que a su vez son matizados por, iii) un parámetro que representa la sensibilidad de los usuarios a los costos de transporte. Así, los costos de transporte -ponderados por el parámetro de la fricción de la distancia- incorporan la variable espacial al índice de accesibilidad, porque implican la localización relativa de los usuarios potenciales (la demanda o población objetivo) y las unidades de servicio (la oferta) existentes en el AMT, así como la conducta espacial de los consumidores. Todo en un marco sistémico, que permite analizar su interrelación de manera conjunta y simultánea.

El índice de accesibilidad probó ser una herramienta de análisis y planeación de aplicación viable en la planeación de ciudades mexicanas. Incorpora algunos de los elementos más importantes que afectan la accesibilidad y permite la simulación de escenarios para apoyar la toma de decisiones. Además es suficientemente claro (lo que permite discutirlo y evaluarlo de manera más objetiva y menos intuitiva), consistente en términos conceptuales (por lo que su diseño es razonablemente confiable) y práctico (lo que significa que puede ser usado cotidianamente para la planeación espacial de servicios urbanos). Por todas estas razones, se puede suponer que vale la pena insertar el índice de accesibilidad que aquí se propone en los observatorios urbanos que actualmente se construyen en México.

Adicionalmente, debe destacarse el apoyo que brindan los SIG (Arc View, en este caso) para la realización de análisis de accesibilidad, ya que facilitan el cálculo de las variables espaciales y la representación cartográfica de la información y los resultados, lo que agiliza y enriquece el análisis. 


\section{Principales hallazgos e implicaciones de politica urbana}

En general, la distribución espacial de la demanda y la oferta del servicio están altamente asociadas en el AMT, lo que indica que la respuesta institucional a los cambios en los patrones de distribución de la población objetivo -los pobres mayores de 65 años y sin seguridad social- ha sido acertada. Esto se refleja tanto en los índices de accesibilidad de cada unidad de salud (destacándose por sus valores más altos las unidades localizadas en el centro de la AMT y las que se localizan en las partes más consolidadas de la ciudad), como en los índices de accesibilidad por AGEB, que varían de manera lógica de acuerdo con la presencia de la población objetivo.

De cualquier manera, siempre es posible identificar áreas de mejora en el diseño e instrumentación de políticas públicas. En este sentido, mediante el índice de accesibilidad se logró identificar zonas de baja accesibilidad, localizadas sobre todo en la periferia del área metropolitana, y clasificarlas según sus niveles de accesibilidad en zonas ganadoras, intermedias y marginadas. En conjunto, estas dos últimas categorías concentran a $80 \%$ del total de la población objetivo que debe ser un eje estratégico de la planeación espacial de los servicios de salud en el área de estudio. Este alto porcentaje, más las elevadas diferencias entre los recorridos mínimos necesarios por AGEB para llegar a la unidad de salud más próxima, evidencian la existencia de discriminación espacial. Esta discriminación se acentúa los fines de semana, cuando cierran $90 \%$ de las unidades.

Finalmente, el análisis de accesibilidad permitió calcular la accesibilidad metropolitana de la población objetivo a los servicios públicos de salud, lo que posibilitará hacer comparaciones en el tiempo para evaluar la respuesta institucional a los cambios en la distribución espacial de la demanda.

Quedan, sin embargo, varias tareas importantes en la agenda de investigación. Destacan, como las más urgentes, contrastar los resultados del índice de accesibilidad con los registros de asistencia de las unidades de salud para probar su capacidad como indicador de accesibilidad revelada. Otra tarea sería automatizar, mediante un programa de cómputo, los procedimientos de cálculo del índice de accesibilidad, la representación gráfica y cartográfica que requiere el análisis, y la generación de los indicadores de desempeño, calidad y desigualdad, para reducir los tiempos de investigación y eliminar los retrabajos. Pero quizá la 
tarea central que se queda en la agenda, sea aplicar el índice de accesibilidad a varias ciudades (de diversos tipos y tamaños), con el fin de aprobar la capacidad del índice que se ha propuesto en este trabajo para apoyar análisis comparativos, o hacer los ajustes necesarios que permitan realizar análisis interurbanos. Esto, sin duda, sería un avance relevante en el área de indicadores urbanos en México. 


\section{Anexo metodológico}

\section{A1. Explicación del cálculo del índice de accesibilidad}

El propósito de este anexo es presentar en detalle el cálculo del índice de accesibilidad, para que el lector pueda analizarlo con mayor facilidad, ponerlo a prueba y, si es de su interés, mejorarlo.

La fórmula para estimar el índice de accesibilidad para cada unidad de servicio (es decir, para la oferta) es la siguiente:

$$
I j=\sum_{i}\left(\frac{S j}{O t o t}\right) C i j^{-b}
$$

Por su parte, la fórmula para estimar el índice de accesibilidad para cada subzona de la ciudad (es decir, para la demanda, o sea el grupo de población objetivo en cada área residencial de la ciudad: en este caso, la población mayor de 65 años sin seguridad social en cada AGEB) es la siguiente:

$$
I i=\sum_{j}\left(\frac{S j}{\text { Otot }}\right) C i j^{-b}
$$

Donde:

Ij $\quad$ Índice de accesibilidad para las unidades de servicios de salud.

Ii $=$ Índice de accesibilidad para el grupo de población objetivo (población mayor de 65 años sin servicios de seguridad social) localizado en cada subzona de la ciudad (AGEB).

$S_{j} \quad=$ Magnitud de los servicios disponibles. En este caso se utiliza la productividad por unidad médica (número de consultas que puede otorgar cada unidad de salud en un cierto periodo).

Otot $=$ Demanda total en la zona de estudio. Es el total de la población objetivo (la población mayor de 65 años sin servicios de seguridad social) de la zona de estudio.

$C_{i j}=$ Costo de transporte. En este ejercicio se utiliza la distancia lineal entre la unidad de salud y los centroides de cada subzona en las que se divide la zona de estudio (en este caso: AGEB).

$b=$ Fricción de la distancia (parámetro que se obtiene por calibración a partir de datos de la conducta espacial de los usuarios). Existen diversos métodos para 
estimarlo. Uno de los más sencillos es calcularlo a partir de la información existente sobre los puntos de origen de los usuarios del servicio. En este caso, de los pacientes de los consultorios médicos. Esta información está disponible en las bitácoras que llevan los médicos de cada consultorio. Lo que se hace es mapear los orígenes de los pacientes que han acudido a cada unidad de servicio (o a una muestra de unidades de servicio) en un cierto lapso, digamos cinco o seis semanas en diferentes meses del año. Luego se trazan cuando menos 10 círculos concéntricos alrededor de las unidades de servicio consideradas. En este caso se trazaron círculos concéntricos a cada 100 metros de las unidades de servicio. Posteriormente se estima la densidad de pacientes en cada "corona"; es decir, en cada área comprendida entre dos círculos concéntricos consecutivos. Luego se grafican en un diagrama cartesiano los valores de densidad de cada corona: en el eje vertical se mide la densidad, y en el eje horizontal, la distancia de la corona a la unidad de servicio. El comportamiento usual es que los valores de densidad de usuarios van disminuyendo conforme se incrementa la distancia a las unidades de servicio. Una vez graficados los puntos de densidad-distancia, se estima su recta de regresión y, especialmente, la pendiente de la recta de regresión. El valor de la pendiente de la recta de regresión es, precisamente, el parámetro de la fricción de la distancia, que de acuerdo con el comportamiento espacial usual de la densidad de usuarios (que disminuye conforme aumenta la distancia a la unidad del servicio), tiene signo negativo.

Con el fin de ilustrar el funcionamiento del modelo, se supone una zona de estudio dividida en tres subzonas $(\mathrm{A}, \mathrm{B}, \mathrm{C})$ donde se localizan dos unidades de salud (X, Y) (figura A1).

Los datos de productividad; es decir, el número de consultas que puede otorgar cada unidad de salud (Sj), se presenta en el cuadro A2; y en el cuadro A3 se presentan los costos de transporte (Cij) entre los centroides de las subzonas y las unidades de salud.

El cálculo del índice de accesibilidad permite conocer la accesibilidad de cada unidad de salud ( $i j$ si se trata de la oferta) y la 
Figura A1

Distribución de los servicios médicos y la población

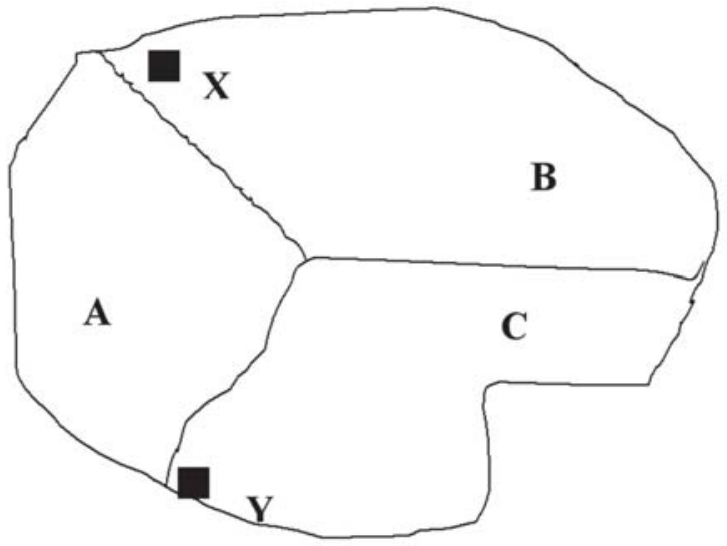

La población objetivo en subzona $(\mathrm{O} i)$ y la población total de la zona de estudio (Otot) se presenta en el cuadro A1.

\section{Cuadro A1}

Población de cada subzona del área de estudio

\begin{tabular}{lc}
\hline Subzona & Población \\
\hline A & 100 \\
B & 200 \\
C & 300 \\
Total & 600 \\
\hline
\end{tabular}

Cuadro A2

Productividad de cada unidad de salud

\begin{tabular}{lc}
\hline Unidades & Consultas \\
\hline $\mathrm{X}$ & 100 \\
$\mathrm{Y}$ & 150 \\
\hline
\end{tabular}

Cuadro A3

Distancia entre los centroides de cada subzona y las unidades de salud

\begin{tabular}{lll}
\hline & $X$ & $Y$ \\
\cline { 2 - 3 } $\mathrm{A}$ & 5 & 4 \\
$\mathrm{~B}$ & 5 & 7 \\
$\mathrm{C}$ & 8 & 3 \\
\hline
\end{tabular}


accesibilidad de cada subzona donde reside la población objetivo (I $i$ si se trata de la demanda). En los cuadros A4 y A5 se ilustra la manera como se realizan los cálculos. Así, la columna Sj/Otot resulta de dividir la oferta de cada una de las clínicas entre la población total demandante (suma de la población de las tres subzonas), y es, por tanto, un indicador de disponibilidad a-espacial que resulta igual para todas las subzonas sin importar su localización respecto a la oferta de los servicios. Pero al incorporar los costos de transporte matizados por la fricción de la distancia $\left(\mathrm{Cij}^{-b}\right)^{36}$ emergen las variaciones espaciales de la accesibilidad. Por ejemplo, la unidad de salud $Y$ es casi tres veces más accesible que la unidad $X$, y la subzona $C$ disfruta de mucha mayor accesibilidad que las subzonas $A$ y $B$. Así, el índice de accesibilidad considera que todos los servicios pueden ser utilizados por cualquiera de los usuarios potenciales sin importar su localización, lo que elimina la distorsión de frontera tan común en los análisis de disponibilidad. La distorsión de frontera se refiere al problema de analizar de manera independiente la disponibilidad de servicios en cada subzona, lo que conduce a suponer erróneamente que la población de las subzonas que no tienen servicios no tiene acceso a ellos. En la realidad, los habitantes localizados en las subzonas que no tienen servicios, acuden a las unidades de servicio localizadas en las subzonas que sí los tienen, porque la idea de subzonas urbanas es una abstracción, un simple recurso metodológico que en nada impide a la población traspasar las fronteras imaginarias que dividen a una subzona urbana de otra.

\section{Cuadro A4}

Cálculo del índice de accesibilidad para unidades de salud

\begin{tabular}{lcccrc}
\hline & $S j$ & $O_{\text {tot }}$ & $S_{j} / O_{i}$ & $C_{i j}^{-b}$ & Accesibilidad \\
\cline { 2 - 6 } $\mathrm{I}_{\mathrm{AX}}$ & 100 & 600 & 0.167 & 55.9 & 0.003 \\
$\mathrm{I}_{\mathrm{BX}}$ & 100 & 600 & 0.167 & 55.9 & 0.003 \\
$\mathrm{I}_{\mathrm{CX}}$ & 100 & 600 & 0.167 & 181.0 & 0.001 \\
Accesibilidad de la unidad X & & & & 0.007 \\
$\mathrm{I}_{\mathrm{AY}}$ & 150 & 600 & 0.250 & 32.0 & 0.008 \\
$\mathrm{I}_{\mathrm{BY}}$ & 150 & 600 & 0.250 & 129.6 & 0.002 \\
$\mathrm{I}_{\mathrm{CY}}$ & 150 & 600 & 0.250 & 15.6 & 0.016 \\
\multicolumn{2}{l}{ Accesibilidad de la unidad Y } & & & & 0.026 \\
\hline
\end{tabular}

${ }^{36}$ La fricción de la distancia (-b) para el caso de este anexo es igual a 2.5. 


\section{Cuadro A5}

Cálculo del índice de accesibilidad para las subzonas residenciales y para toda la zona de estudio

\begin{tabular}{lcrc}
\hline Subzona residencial A & $I_{A X}$ & $I_{A Y}$ & Accesibilidad \\
& 0.003 & 0.008 & 0.011 \\
Subzona residencial B & $I_{B X}$ & $I_{B Y}$ & \\
& 0.003 & 0.002 & 0.005 \\
Subzona residencial C & $I_{C X}$ & $I_{C Y}$ & \\
& 0.001 & 0.016 & 0.017 \\
\multicolumn{2}{l}{ Total de la zona de estudio a los servicios de salud } & 0.033 \\
\hline
\end{tabular}

\section{A2. Simulación de escenarios}

El índice de accesibilidad también puede servir para la generación de escenarios para apoyar las tareas de planeación espacial de los servicios y contestar preguntas del tipo ¿̇qué pasaría si...? Por ejemplo, ¿que pasaría con los niveles de accesibilidad si se instala una nueva unidad médica en la zona de estudio (en un determinado sitio)?; o bien, ¿que pasaría si aumenta o disminuye la población de una subzona?, o ¿qué pasaría si se aumenta o disminuye la oferta de los servicios de salud?, ¿̇o si cambian todas esas variables simultáneamente? A continuación se muestra cómo se puede generar un escenario para anticipar los efectos en la accesibilidad derivados de instalar una nueva unidad de salud en la zona de estudio.

\section{Construcción de un escenario}

Supóngase que se construye una nueva unidad de salud $Z$, en la subzona $B$ casi en el límite con las subzonas $A$ y $C$ (figura A2), con una productividad de 300 consultas.

Al recalcular los índices de accesibilidad se genera un escenario en el que la nueva unidad de salud $Z$ tiene la mayor accesibilidad en el sistema, superando por mucho los niveles de accesibilidad de la unidad $X$ y, sobre todo, los de la unidad $Y$ (cuadro A9). Esta situación obedece al mayor volumen de consultas que puede ofertar la unidad $Z$ y a que se ve favorecida por su localización (la suma de las distancias de los tres orígenes a la unidad $Z$ es de 15 , contra 18 de la unidad X y 14 de la Y).

En términos de los impactos en las subzonas, la construcción de una unidad de salud adicional en la subzona $B$ eleva significativamente la accesibilidad de esta subzona, superando por mucho los niveles de accesibilidad de las subzonas $A$ y $C$ (cuadro A10). 
Figura A2

Distribución de los servicios médicos y la población

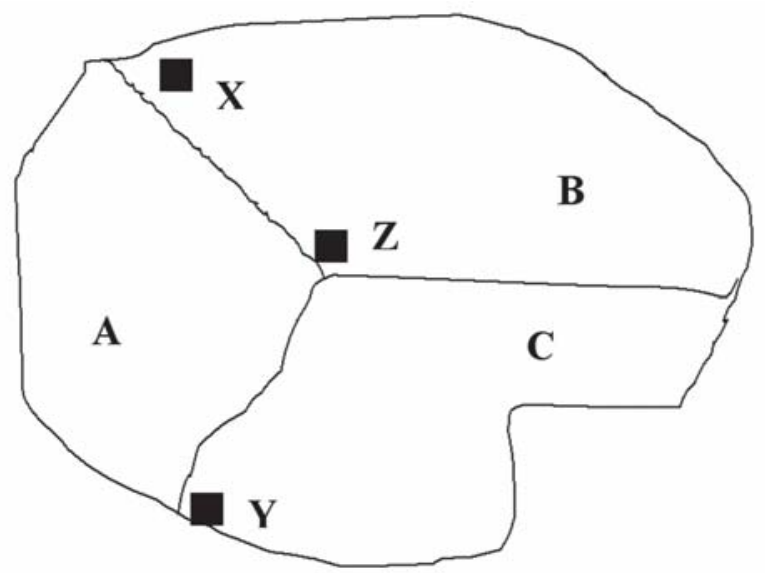

Las entradas para el cálculo de los nuevos índices de accesibilidad se presentan en los cuadros A6, A7 y A8, y los resultados se muestran en los cuadros A9 y A10.

\section{Cuadro A6}

Población de cada subzona del área de estudio

\begin{tabular}{lc}
\hline Subzona & Población \\
\hline $\mathrm{A}$ & 100 \\
$\mathrm{~B}$ & 200 \\
C & 300 \\
Total & 600 \\
\hline
\end{tabular}

\section{Cuadro A7}

Productividad de cada unidad de salud

\begin{tabular}{lc}
\hline Unidades & Consultas \\
\hline $\mathrm{X}$ & 100 \\
$\mathrm{Y}$ & 150 \\
$\mathrm{Z}$ & 300 \\
\hline
\end{tabular}




\section{Cuadro A8}

Distancia entre los centroides de cada subzona y las unidades de salud

\begin{tabular}{cccc}
\hline & $X$ & $Y$ & $Z$ \\
\cline { 2 - 4 } $\mathrm{A}$ & 5 & 4 & 8 \\
$\mathrm{~B}$ & 5 & 7 & 2 \\
$\mathrm{C}$ & 8 & 3 & 5 \\
\hline
\end{tabular}

\section{Cuadro A9}

Cálculo del índice de accesibilidad para unidades de salud

\begin{tabular}{|c|c|c|c|c|c|}
\hline & $S j$ & $\mathrm{O}_{t o t}$ & $S_{j} / O_{i}$ & $C_{i j}^{-b}$ & Accesibilidad \\
\hline $\mathrm{I}_{\mathrm{AX}}$ & 100 & 600 & 0.167 & 55.9 & 0.003 \\
\hline$I_{B X}^{A X}$ & 100 & 600 & 0.167 & 55.9 & 0.003 \\
\hline $\mathrm{I}_{\mathrm{CX}}$ & 100 & 600 & 0.167 & 181.0 & 0.001 \\
\hline \multicolumn{5}{|c|}{ Accesibilidad de la unidad X } & 0.007 \\
\hline$I_{A Y}$ & 150 & 600 & 0.250 & 32.0 & 0.008 \\
\hline$I_{B Y}^{A I}$ & 150 & 600 & 0.250 & 129.6 & 0.002 \\
\hline $\mathrm{I}_{\mathrm{CY}}^{\mathrm{BY}}$ & 150 & 600 & 0.250 & 15.6 & 0.016 \\
\hline \multicolumn{5}{|c|}{ Accesibilidad de la unidad Y } & 0.026 \\
\hline$I_{A Z}$ & 300 & 600 & 0.500 & 181.0 & 0.003 \\
\hline$I_{B Z}^{A Z}$ & 300 & 600 & 0.500 & 5.7 & 0.088 \\
\hline $\mathrm{I}_{\mathrm{CZ}}$ & 300 & 600 & 0.500 & 55.9 & 0.009 \\
\hline \multicolumn{5}{|c|}{ Accesibilidad de la unidad Z } & 0.100 \\
\hline
\end{tabular}

\section{Cuadro A10}

Cálculo del índice de accesibilidad para las subzonas residenciales y para toda la zona de estudio

\begin{tabular}{lrrrc}
\hline Accesibilidad de la zona A & $I_{A X}$ & $I_{A Y}$ & $I_{A Z}$ & Accesibilidad \\
& 0.003 & 0.008 & 0.003 & 0.014 \\
Accesibilidad de la zona B & $I_{B X}$ & $I_{B Y}$ & $I_{B Z}$ & \\
& 0.003 & 0.002 & 0.088 & 0.093 \\
Accesibilidad de la zona C & $I_{C X}$ & $I_{C Y}$ & $I_{C Z}$ & \\
\multicolumn{5}{l}{ Total de la zona de estudio a los servicios de salud } \\
\hline
\end{tabular}




\section{Bibliografía}

Agyemang-Duah, Kwauku y Frederick L. Hall (1997), "Spatial Transferability of an Ordered Response Model of Trip Generation", Transport Research A, 31 (5): 389-402.

Bach, L. (1981), “The Problem of Aggregation and Distance for Analyses of Accessibility and Access Opportunity in Location-allocation Models", Environment and Planning A, 13: 955-978.

Bath, Chandra, Susan Handy, Kara Kockelman y Hani Mahmassani (2000), Development of an Urban Accesibility Index: Literature Review, Research Report number 7-4938-1, Center for Transportation Research, The University of Texas at Austin.

Birkin, Mark, Graham Clarke y Martin P. Clarke (2002), Retail Intelligence and Network Planning, John Wiley \& Sons, Nueva York.

Cervero, Robert, Timothy Rood y Bruce Appleyard (1999), “Tracking Accessibility: Employment and Housing Oportunities in the San Francisco Bay Area", Environment and Planning A, 31: 1259-1278.

Drezner, Zvi y Horst W. Hamacher (2001), Facility Location: Application and Theory, Springer-Verlag, Nueva York.

Dupuy, Gabriel y Vaclav Stransky (1996), “Cities and Highways Networks in Europe”, Journal of Transport Geography, 4 (2): 107-121.

Fortney, John C., Kathryn Rost, Mingliang Zhang y John Warren (1999), "The Impact of Geographic Accessibility on the Intensity and Quality of Depression Treatment", Medical Care, 37: 884-893.

Garrocho, Carlos (1990a), "Servicios de salud y planeación regional en el Estado de México", Estudios Territoriales, Madrid, vol. 33: 55-72. 
(1990b), "Localización geográfica de los servicios de salud en un subsistema de asentamientos rurales: un intento de evaluación”, Estudios Demográficos y Urbanos, El Colegio de México, vol. 5: 127-148.

(1993a), "De la casa al hospital: un enfoque espacio-temporal”, Estudios Sociológicos, El Colegio de México, XI (32): 547-554.

(1993b), "Análisis de accesibilidad a los servicios de salud y los sistemas de información geográfica: teoría y aplicación en el contexto del Estado de México", Estudios Demográficos y Urbanos, El Colegio de México, vol. 8 (2): 427-444.

(1993c), "Eficiencia, igualdad y equidad en la localización de los servicios de salud infantil del Estado de México", Estudios Demográficos y Urbanos, El Colegio de México, vol. 8 (3): 601-640.

(1995), Análisis socioespacial de los servicios de salud: accesibilidad, utilización y calidad, El Colegio MexiquenseDIF Estado de México, México.

(2000), "Justicia social y servicios públicos: los factores no espaciales que afectan la utilización de los servicios de salud", en E. Patiño y J. Castillo, Ciudad, salud y medio ambiente, Red Nacional de Investigación Urbana-Universidad Autónoma de Puebla, Puebla, México.

(2004), “Localización, localización, localización: el manejo del espacio en la competencia entre centros comerciales”, Estudios Demográficos y Urbanos, El Colegio de México (en prensa).

, Tania Chávez y José Antonio Álvarez (2003), La dimensión espacial de la competencia comercial, El Colegio Mexiquense-UaEm, México.

Juan Campos (2005), "Distribución espacial de la población mayor de 65 años en la zona metropolitana de Tolu- 
ca, 1990-2000”, Estudios Demográficos y Urbanos, El Colegio de México (enviado).

Ghosh, Avijit y Sara L. McLafferty (1987), Location Strategies for Retail and Services Firms, Lexington Books, Nueva York.

Goodall, Brian (1987), The Penguin Dictionary of Human Geography, Penguin Books, Londres.

Goodman, David C., Ellior S. Fisher, George A. Little, Therese A. Stukel y Chiang-hua Chang (2001), "Are Neonatal Intensive Care Resources Located According to Need?", Pediatrics, 108: 426-431.

Guagliardo, Mark F. (2004), "Spatial Accessibility of Primary Care: Concepts, Methods and Challenges", International Journal of Health Geographics, 3: 3-26 (http://www.ijhealthgeographics.com/content/3/1/3).

Gulliford, Martin C. (2002), "Availability of Primary Care Doctors and Population Health in England: Is there an Association?", Journal of Public Health and Medicine, 24: 252-264.

Guy, Cliff M. (1983), “The Assessment of Access to Local Shopping Opportunities: A Comparison of Accessibility Measures", Environment and Planning B: Planning and Design, 10: 219-238.

Hägerstrand, Torsten (1970), "What about People in Regional Science", Papers of the Regional Science Association, 14: 7-21.

Handy, Susan L. (1993), "Regional versus Local Accessibility: Neo-traditional Development and its Implications for Non-work Travel”, Built Environment, 18 (4): 253-267.

y Debbie A. Neimeier (1997), "Measuring Accessibility: An Exploration of Issuess and Alternatives", Environment and Planning A, 29: 1175-1194. 
Hardcastle, David e Ian Cleeve (1995), Accessibility Modelling using GIS, Geographic Information Systems, PTRC European Transportation Forum, University of Warwic, Inglaterra.

Harner, John, Kee Warner, John Pierce y Tom Huber (2002), "Urban Environmental Justice Indices", The Professional Geographer, 54 (3): 318-381.

Hillman, Richard y Graham Pool (1997), “GIs-based Innovations for Modelling Public Transportation Accessibility”, Traffic Engineering and Control, 30 (10): 554-559.

Ikhrata, Hasan M. y Paul Michell (1997), “Technical Report of Southern California Association of Governments Transportation Performance Indicators", Transportation Research Record 1606: 103-114.

Ingram, David R. (1971), “The Concept of Accessibility: A Search for an Operational Form”, Regional Studies, 5: 101107.

Johnston, Ronald J., Derek Gregory y David. M. Smith (2000), The Dictionary of Human Geography, Blackwell, Oxford, Inglaterra.

Joseph, Alun E. y David R. Phillips (1984), Accessibility and Utilization: Geographical Perspectives on Health Care Delivery, Harper and Row, Londres.

Kingsley, G. Thomas (1998), Neighborhood Indicators: Taking Advantage of the New Potential, National Neighborhood Indicators Partnership, The Urban Institute, Estados Unidos.

Knox, Paul L. (1978), “The Intraurban Ecology of Primary Medical Care: Patterns of Accessibility and their Policy Implications", Environment and Planning A, 10: 415-435.

Koening, J. G. (1980), “Indicators of Urban Accessibility: Theory and Application", Transportation, 9: 145-172. 
Kwan, Mei-Po (1998), "Space-time and Integral Measures of Individual Accessibility: A Comparative Analysis using a Point-based Framework", Geographical Analysis, 30 (3): 191-216.

Lee, Ming S. y Michael G. McNally (1998), Application of Space-time Prisms for the Measure of Accessibility, Institute of Transportation Studies, University of California, Irvine, Report Number UCI-ITS-AS-WP-98-2.

Luo, Wei (2004), "Using a GIs-based Floating Catchment Method to Assess Areas with Shortage of Physicians", Health and Place, 10: 1-11.

y Fahui Wang (2003), “Measures of Spatial Accessibility to Health Care in a GIS Environment: Synthesis and a Case Study in Chicago Region”, Environment and Planning B, 30 (6): 865-884.

Martínez, Francisco J. (1995), "Access: The Transport-land Use Economic Link", Transportation Research B, 29 (6): 457470.

Meden, Terry, Celeste St. John-Larkin, Deborah Hermes y Stephen Sommerschield (2002), "Relationship between Travel Time Distance and Utilization of Breast Cancer Treatment in Rural Northern Michigan", Journal of the American Medical Association, 287 (1): 111.

Miller, Harvey J. (1999), “Measuring Space-time Accessibility Benefits within Transportation Networks: Basic Theory and Computational Procedures", Geographical Analysis, 31 (2): 187-212.

Morris, J. M., P. L. Dumble y M. R. Wigan (1979), “Accessibility Indicators for Transport Planning”, Transport Research A, 13A: 91-109.

Niemeier, Debbie A. (1997), "Accessibility: An Evaluation using Consumer Welfare”, Transportation, 24: 377-396. 
Partida, Virgilio (2001), "Monto y estructura de la población en el año 2000 y perspectivas en el 2050", Demos Carta Demográfica sobre México 2001, Instituto de Investigaciones Sociales, unam, México.

Phillips, David R. (1990), Health and Health Care in the Third World, Longman, Hong Kong.

Pooler, James A. (1995), "The Use of Spatial Separation in the Measurement of Transport Accessibility", Transport Research A, 29A (6): 421-427.

Rosenberg, Mark y John Everitt (2001), "Planning for Aging Populations: Inside or Outside the Walls", Progress in Planning, octubre, 56: 119-168

Scarpaci, Joseph (1989), Primary Medical Care in Chile: Accessibility under Military Rule, University of Pittsburgh Press, Pittsburgh.

Sedesol (Secretaría de Desarrollo Social) (2005), Reglas de Operación del Programa de Desarrollo Humano Oportunidades, Coordinación Nacional de Oportunidades, México.

Song, Shunfeng (1996), "Some Tests of Alternative Accessibility Measures: A Population Density Approach”, Land Economics, 72 (4): 474-482.

Sweet, R.J. (1997), "An Aggregate Measure of Travel Utility", Transportation Research B, 31 (5): 403-416.

TDM (2003), TDM Encyclopedia, www.vtpi.org, Victoria Transport Policy Institute, Victoria, Canadá.

Tuirán, Rodolfo (1999), "Desafíos del envejecimiento demográfico en México", en Envejecimiento demográfico en México: retos y perspectivas, Consejo Nacional de Población, México.

un-Habitat (2005a), 1000 Cities Programme, http://www.unhabitat. org/programmes/guo/muip.asp. 
(2005b), Financing Urban Shelter: Global Report on Human Settlements, 2005, Ginebra, Suiza.

Verroen, Erik J. y Hans D. Hilbers (1996), Urban Planning and Mobility, Some Dutch Experiences, TNo Institute for Transportation, Holanda.

Voges, E. M. y A. H. Naudé (1983), Accessibility in Urban Areas: An Overview of Different Indicators, Technical Report RT/ 21/83, National Institute of Transport and Road Research, CSIR, Sudáfrica.

Wang, Donggen y Harry Timmermans (1996), Activity-based Measures of Accessibility of Transportation Policy Analysis, Transportation Planning Methods, PTRC European Tansport Forum, Brunel University, Inglaterra.

Weibull, Jörgen W. (1976), "An Axiomatic Approach to the Measurement of Accessibility", Regional Science and Urban Economics, 6: 357-379.

Whitelegg, John (1982), Inequalities in Health Care: Problems of Access and Provision, Straw Barnes Press, Retford, Inglaterra.

Wilson, Alan G. (1971), "A Family of Spatial Interaction Model, and Associated Developments", Environment and Planning, 3: 1-32.

Zhang, Ming, Qing Shen y Joseph Sussman (1998), "Job Accessibility in the San Juan Metropolitan Region”, Transportation Research Record 1618: 22-31.

Recibido: 26 de julio de 2005. Reenviado: 9 de enero de 2006. Reenviado: 6 de abril de 2006. Aceptado: 20 de abril de 2006. 
Carlos Garrocho. Maestro en desarrollo urbano (El Colegio de México, 1997) y doctor en geografía social (Universidad de Exeter, Inglaterra, 1992). Profesor-investigador de El Colegio Mexiquense, A.C. desde 1986 y miembro del Sistema Nacional de Investigadores desde 1987. Autor de varios libros y diversos artículos sobre geografía urbana, accesibilidad y localización a servicios públicos y privados. Recientemente participó en la evaluación nacional del Programa de Desarrollo Humano Oportunidades, y está terminando, en colaboración, el Observatorio de la Zona Metropolitana de Toluca. Actualmente, su trabajo de investigación se centra en la geografía urbana de la zona metropolitana de Toluca.

Juan Campos Alanís. Maestro en estudios regionales (Instituto Mora, 2001), y actualmente cursa los estudios de doctorado en geografía en la Universidad Nacional Autónoma de México. Profesor de tiempo completo definitivo de la Facultad de Geografía de la Universidad Autónoma del Estado de México. Autor de artículos sobre la política de combate a la pobreza y envejecimiento demográfico. Actualmente, su temática de investigación se orienta al análisis de la marginación social y estudios sobre la pobreza urbana y regional. 